\title{
GAUDÍ Y LAS BOVEDAS DE LAS ESCUELAS DE LA SAGRADA FAMILIA
}

\author{
(GAUDÍ AND THE VAULTS OVER THE ‘SAGRADA FAMILIA’ SCHOOL)
}

\section{Josep $\mathrm{M}^{\mathrm{a}}$ Adell}

Profesor, Doctor Arquitecto. Universidad Politécnica Madrid (UPM). Dpto. Construcción y Tecnología Arquitectónicas (DCTA). Escuela Técnica Superior de Arquitectura (ETSAM). Director Línea Investigación sobre fábricas en el Grupo de Investigación de Tecnologías Innovadoras y Sostenibles en Edificación (tise-fábricas). Presidente del 12 ${ }^{\text {th }}$ IBMAC 2000.

\section{Alfonso García Santos \\ Doctor Arquitecto. DCTA-UPM-ETSAM-TISE}

ESPAÑA

\section{RESUMEN}

Las pequeñas Escuelas de Gaudi, a los pies de la Sagrada Familia, son la joya de la Arquitectura modernista en ladrillo, que ha permanecido ensombrecida por el Templo que, como un gigante, las ha estado pisando durante 7 años (1995-2002), con la indiferencia con la que se ignora a un pobre que pide a las puertas de una iglesia.

Se construyeron en el año 1909 con carácter provisional para los párvulos de los obreros, sabiendo que su ubicación impedía terminar el Templo. Durante la guerra civil, fueron incendiadas un par de veces (1936 y 1938), y se rehabilitó su cubierta en 1940 por Quintana, sucesor de Gaudi, con las variaciones respecto del original que ahora se ponen de manifiesto con esta investigación.

\begin{abstract}
Durante 15 años el Prof. Adell, en contacto con la Junta Constructora del Templo (J.C.T.), hizo múltiples propuestas para que se trasladaran las escuelas de forma integra a una mejor ubicación. Ante el rápido crecimiento de la planta del templo, y sin poderlo impedir, en el año 2000 la J.C.T. cortó la esquina noreste para añadir un pilar a la nave principal del Templo. Posteriormente, en el año 2002, con el $150^{\circ}$ aniversario del nacimiento de Gaudí, la J.C.T. apresuradamente, decidió despedazarlas para reconstruirlas manteniendo sólo 3 de esos pedazos, a pesar de la oposición pública que el Prof. Adell manifestó en el Ateneo de Barcelona y en los periódicos.
\end{abstract}

De nada sirvió que un monumento histórico artístico que se había propuesto trasladar por flotación de forma íntegra a la plaza colindante o a otra parte del solar de la S.F., se destrozara para reconstruirla con errores y sin apenas mantener el original.

Tampoco fue tomada en consideración la propuesta de nueva cubierta planteada por el Prof. Adell junto con el Arquitecto Eladio Dieste que hubiera supuesto la evolución tecnológica que a Gaudi le hubiera gustado, en esta obra experimental, donde combinaba las técnicas y las formas con gran originalidad en los inicios de su creación arquitectónica.

Fecha de recepción: 2-III-05

\section{SUMMARY}

The tiny Gaudi School that once stood at the foot of the 'Sagrada Familia' is a gem of modernist brick architecture that has been overshadowed and even trampled on (for 7 years, from 1995 to 2002) by its gigantic neighbour, an atrocity that met with the same indifference as a beggar outside a church door.

It was built in 1909 as a provisional structure for the education of the workers' children in the full awareness that it would have to be demolished to finish the temple. In 1940, Quintana rehabilitated the roof to repair the damage caused by two fires that broke out during the civil war (1936 and 1939), although with variations on the original design, as shown in the present study.

Over a period of 15 years Prof. Adell raised several proposals to the Temple Construction Council (abbreviated in Spanish as J.C.T.), to remove the school, all in one piece, to a better location. Due to the rapid progress on temple construction, nothing could be done in 2000 to prevent the J.C.T. from cutting off the northwest corner to make room for one of the columns that supports the main nave. Subsequently, in 2002, on the $150^{\circ} \mathrm{h}$ anniversary of Gaudi's birth, despite Prof. Adell's public opposition in forums such as the Ateneo de Barcelona and in the press, the J.C.T. hastily decided to move the school by sections and partially rebuild it with only three of the pieces.

But the objections and the proposal to use flotation techniques to relocate this historic-artistic monument as a single unit to the adjacent square or to the other side of the S.F. compound were to no avail and unable to prevent the destruction of the school and its erroneous reconstruction, which bears little or no resemblance to the original.

Nor was Prof. Adell's proposal for a new roof, designed in conjunction with architect Eladio Dieste, accepted, even though this solution entailed the sort of technological evolution that Gaudi would have liked for this experimental work, in which he combined technique and form in very original ways in the early stages of his most ambitious architectural project. 


\section{LAS ESCUELAS ORIGINALES DE GAUDÍ (1909), IN- CENDIADAS (1936) Y RECONSTRUIDAS (Quintana, 1940)}

Las Escuelas de Gaudí, situadas en el solar de la Sagrada Familia, tienen una planta de proporción rectangular de unos $12 \times 24 \mathrm{~m}$, con acceso por el centro de la fachada frontal, y con los patios a la fachada posterior. Las paredes son en su totalidad curvilíneas, albergando, además del cuerpo de acceso, los aseos junto a los extremos de los laterales menores. La cubierta ondulada apoya en su eje central sobre una viga que descansa entre soportes (Fig.I.1.a).

Su interior se dividía en 3 aulas con los soportes y la viga central a la vista, así como los tablones que conformaban la curvatura de la bóveda tabicada dispuesta sobre ellos (Fig.I.1.b).

Las Escuelas fueron incendiadas el 20 de julio de 1936 durante la Guerra Civil, afectando a la totalidad de la cubierta, que se derrumbó ya que estaba apoyada sobre tablones de madera, nuevamente fueron reconstruidas dos veces por el Arquitecto Quintana, siendo la cubierta actual la de la segunda reconstrucción del año 1940.

Como puede apreciarse, sólo quedaron de pie, las paredes perimetrales y la viga doblada por el efecto del calor, sobre los soportes, habiendo desaparecido casi por completo la cubierta ondulada después de arder los tablones que la sustentaron. Esto evidencia que la estructura empleada no soportaba la acción del fuego (Fig.I.2.a).

La planta de las Escuelas resultaba de conformar el perímetro ondulado de 3 corazones entrelazados entre sí, y de cuyos centros se elevaban los soportes que sujetaban la viga central.

El acceso principal estaba centrado en su frente y las salidas a los patios de las aulas se ubicaban como apéndices en los extremos laterales opuestos, además de otra en el centro de la fachada posterior (Fig.I.2.b).
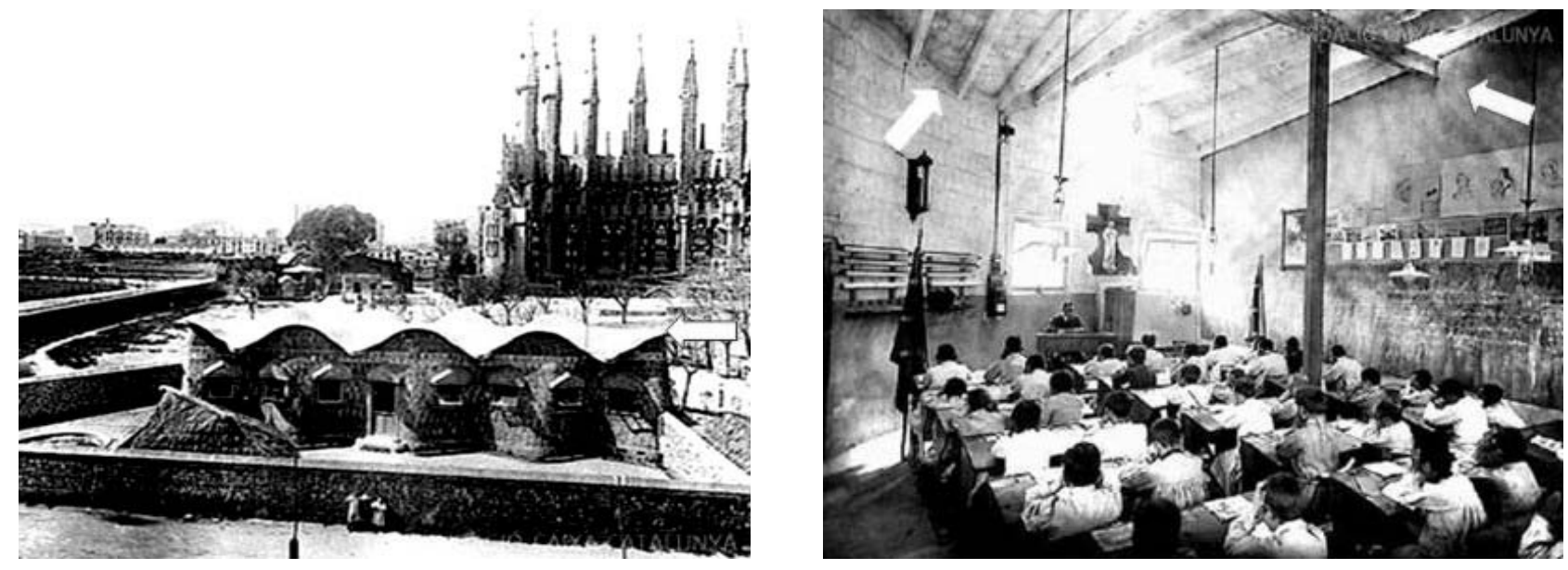

Fig. I.1. a) Fotografia de las Escuelas de la Sagrada Familia antes de ser incendiadas en 1936, vista frontal al alzado que da al jardín posterior (obsérvese la cresta horizontal sobre la viga longitudinal central de la cubierta); b) Interior de las Escuelas de la Sagrada Familia con la viga central y los tablones que apoyan en ella.
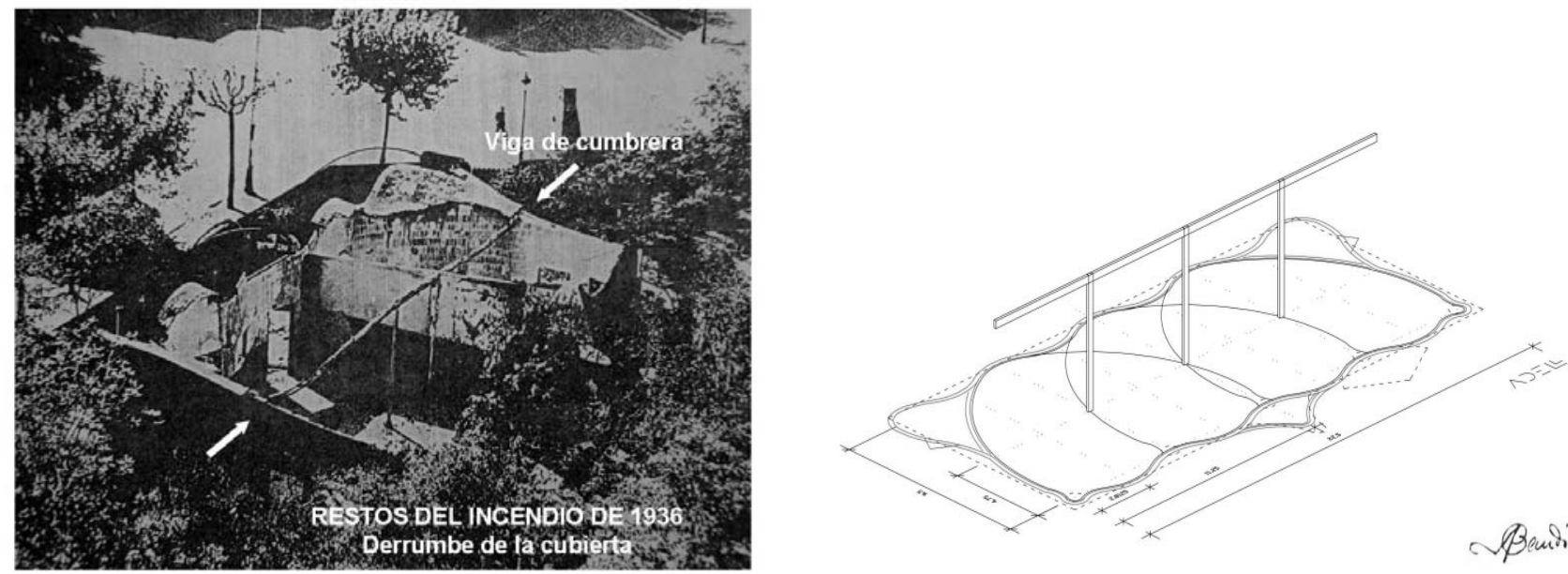

Fig. I.2. a) Foto de las Escuelas de la Sagrada Familia incendiadas, donde se aprecia el derrumbe de la cubierta frente a la permanencia de las paredes en pie, asi como la deformación de la viga central metálica por efecto del fuego; b) Dibujo que representa la planta de las Escuelas con las paredes onduladas conformando 3 corazones de cuyos centros emergen los pilares que soportan la viga central. 

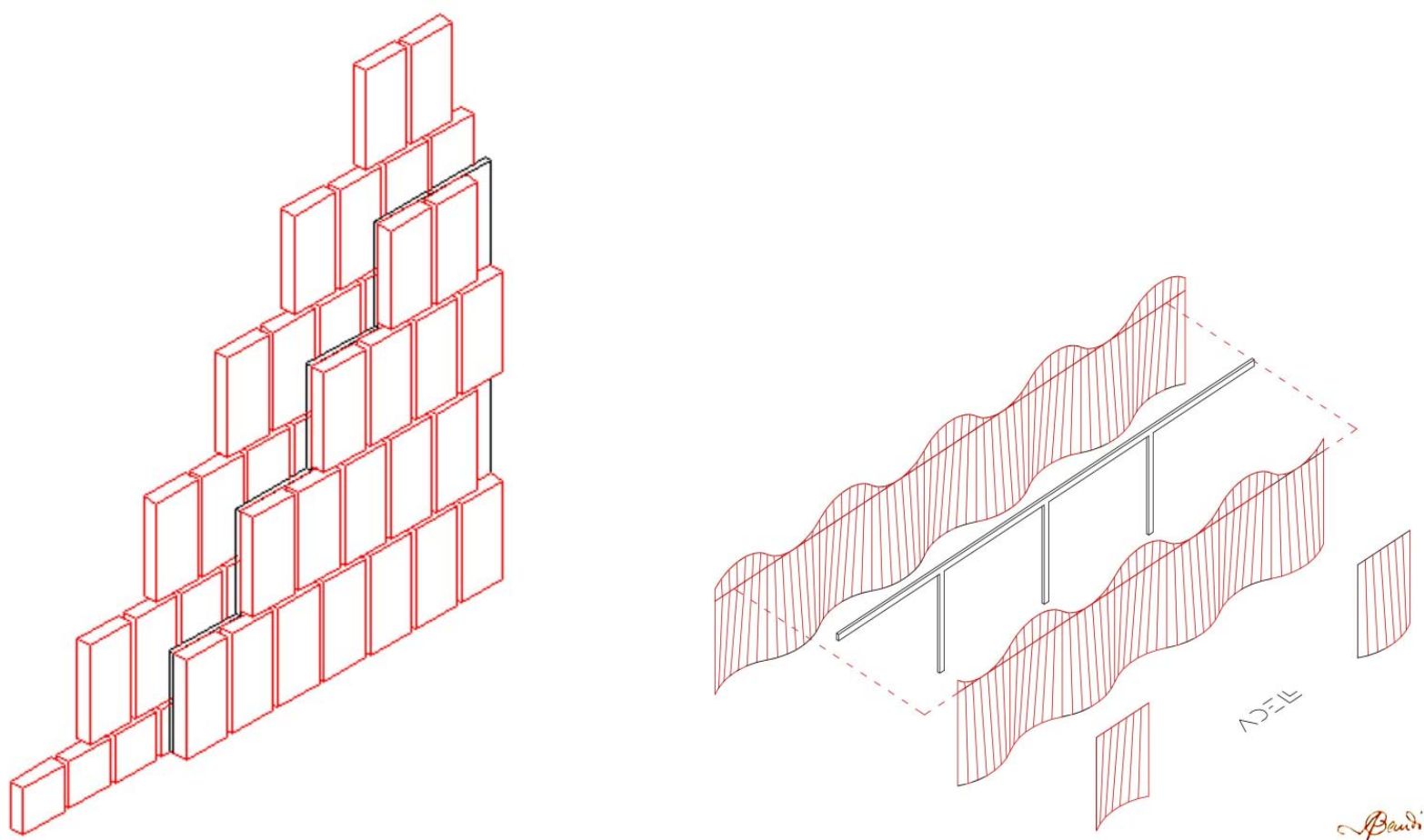

Fig. I.3. a) Detalle de la organización constructiva del tabicado doblado de las Escuelas de Gaudi, con el ladrillo dispuesto vertical mostrando su tabla al exterior; b) Perspectiva con las paredes onduladas longitudinales y los conoides empleados para su ejecución.
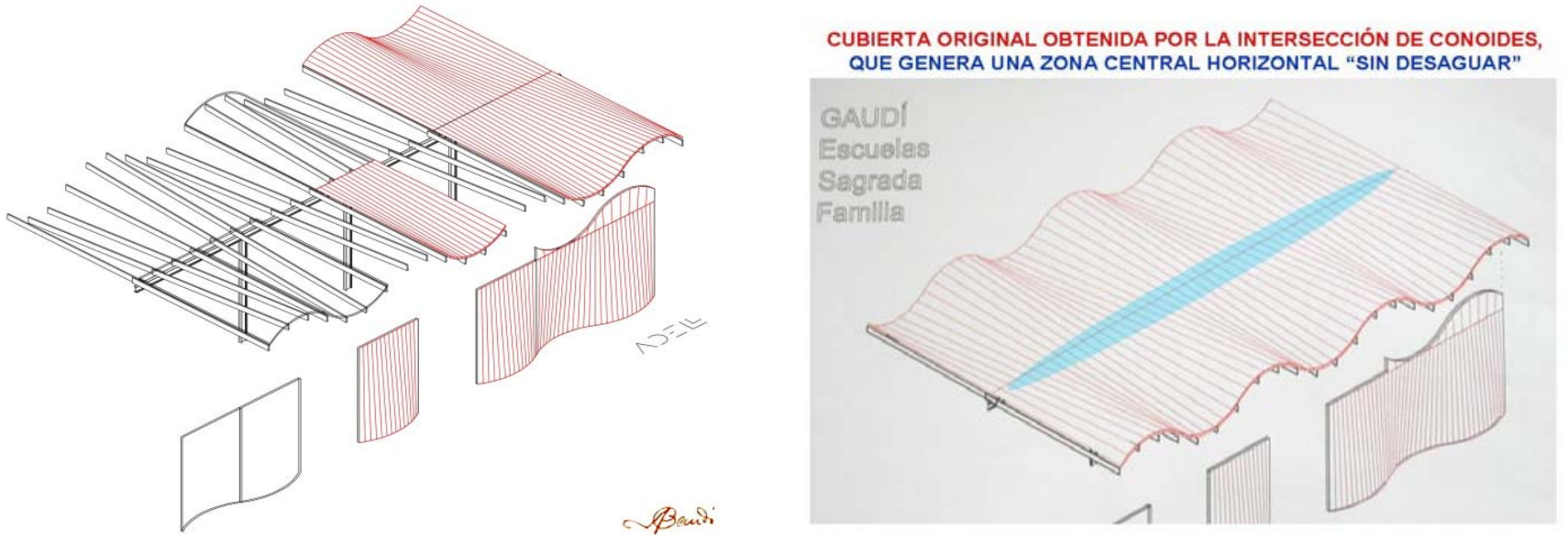

Fig.I.4. a) Paredes onduladas de conoides con su parte superior recta entre las ondas de la cubierta. Conoides de la cubierta apoyados sobre tablones que, a su vez, descansan sobre la viga central y la fachada; b) Remanso de agua que se produce en la zona central de la cubierta, por deformación del apoyo discontinuo de los tablones sobre la viga central.

Las paredes están construidas con un tabique doblado ondulado, de apenas $9 \mathrm{~cm}$ de grueso total, que es la suma resultante del doble grueso del ladrillo $(29 \times 14 \times 4 \mathrm{~cm})$ junto con su mortero $(4+4+1 \mathrm{~cm})$. Tiene además la originalidad de tener los ladrillos del tabique dispuestos verticalmente mostrando sus tablas al exterior) (Fig.I.3.a).

Gaudí, con esta peculiar disposición de las piezas, separadas $15 \mathrm{~cm}$ entre sí, logró que la curvatura de las paredes fuera lo más fluida posible, lo que tiene especial influencia al practicar la mayor curvatura en el encuentro de los extremos de las fachadas frontales largas con las laterales cortas (Fig.I.3.b).

La cubierta se construyó como una bóveda tabicada (de 2 ó 3 hojas), componiendo un conjunto de conoides contrapuestos, cóncavos y convexos, en lo que a su curvatura vertical se refiere, unidos entre sí en la línea recta dispuesta sobre el eje central del edificio. Dichos conoides estaban formados por las generatrices rectas de los tablones de madera, que se apoyaban en la viga central y en las fachadas longitudinales.

Estos tablones salvaban la distancia entre la viga central de las Escuelas, constituida como directriz horizontal, y cada una de las paredes de las fachadas principales, constituidas como directriz curva o sinusoidal. Sobre la viga sobresalía una cresta central (Fig.I.4.a)

$\mathrm{Al}$ tratarse de una cubierta de viguetas con tablones de unos $5 \mathrm{~m}$ de longitud (y no de $10 \mathrm{~m}$ como inicialmente podría pensarse), apoyadas sobre una viga central, era inevitable que con la deformación del apoyo en el tiempo, se propiciara un agrietamiento central o una contrapendiente en el centro de la cubierta, que impidiera la evacuación del agua o produjera humedades (Fig.I.4.b). 

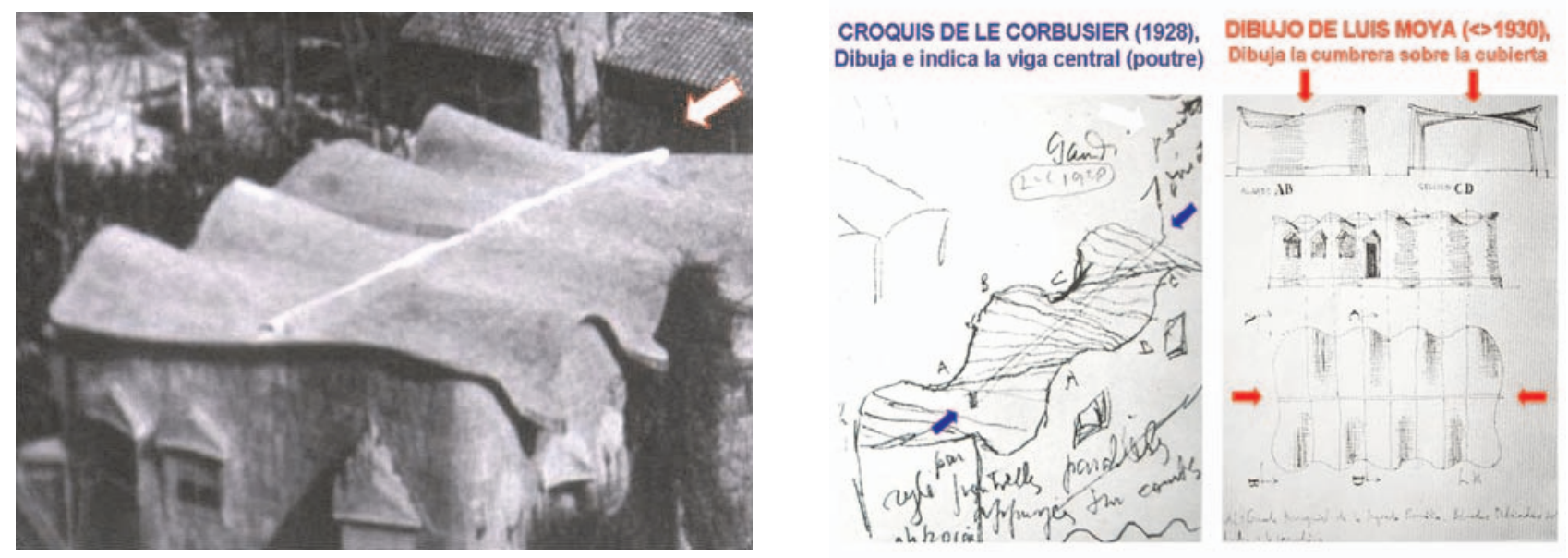

Fig. I.5. a) Fotografia de las Escuelas antes de ser incendiadas, que muestra, claramente a la vista, la cresta existente sobre la viga longitudinal central de la cubierta a dos aguas; b) Dibujo de Le Corbusier en su bloc de notas (1929), donde expresa la volumetría ondulada de la cubierta de las Escuelas de Gaudí, dibujando sobre ellas "a la vista", la viga central, cuya denominación en francés (poutre), la escribe encima del gráfico / / Dibujo de Luis Moya de las Escuelas de Gaudi antes de su incendio, que muestran con claridad, en alzados frontal y lateral, sección transversal y planta de cubierta, que la cubierta original, antes de incendiarse, estaba dividida en 2 faldones, por el remate superior en cresta de la viga longitudinal central.
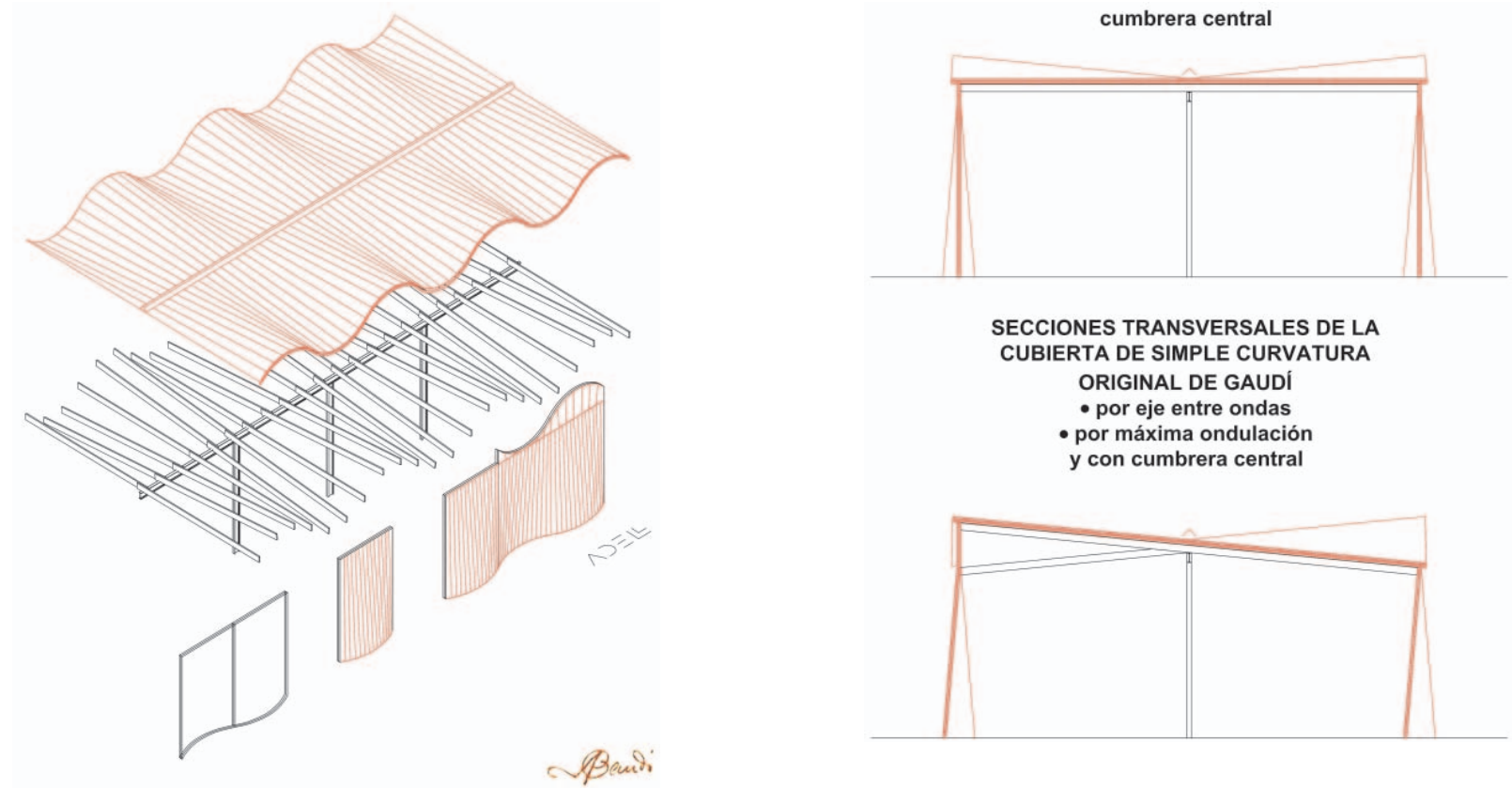

Fig.I.6. a) Perspectiva mostrando la superposición de la cubierta sobre los tablones donde apoya y, de éstos, sobre la viga central y la fachada ondulada, donde descargan. Obsérvese la cumbrera central; b) Secciones transversales de la cubierta, por la intersección horizontal entre conoides o por el eje inclinado de los mismos, con su cumbrera central.

Esta circunstancia, no se sabe si desde su inicio o con posterioridad a su construcción (por problemas de humedad), obligó a disponer una cumbrera central, dividiendo la cubierta en 2 aguas, vertiendo cada una de ellas a fachadas contrapuestas (Fig.I.5.a).

Le Corbusier dibujó en su bloc de notas, de forma expresiva, la envolvente volumétrica del edificio, y, sobre ella, resalta gráficamente la viga, y además añade por escrito su nombre en francés (poutre), dejando así claro, sin ningún género de dudas, que el nervio central de la cubierta estaba superiormente a la vista desde el exterior, tal y como se puede apreciar en las fotografías de la época previas al incendio de la cubierta (Fig.I.5.b.1).
También el Arquitecto Luis Moya Blanco, conocido por su importante obra por él realizada con arcos y bóvedas tabicadas, visitó las Escuelas de la Sagrada Familia en Barcelona, antes de que éstas fueran quemadas y su techumbre derrumbada. Como auténtico profesional de la materia que era, elaboró un croquis de especialista en la construcción tabicada, con un dibujo que deja bien claro, y sin ningún género de dudas, que la cubierta original de las Escuelas de Gaudí, tenía la viga central sobresaliendo, a modo de cresta, dividiendo longitudinalmente por la mitad de la cubierta en dos faldones (Fig.I.5.b.2).

Rehaciendo pues el esquema estructural de las Escuelas de la Sagrada Familia en volumetría y sección, queda claro que el 


\section{ESCUELAS SAGRADA FAMILIA DE GAUDÍ}
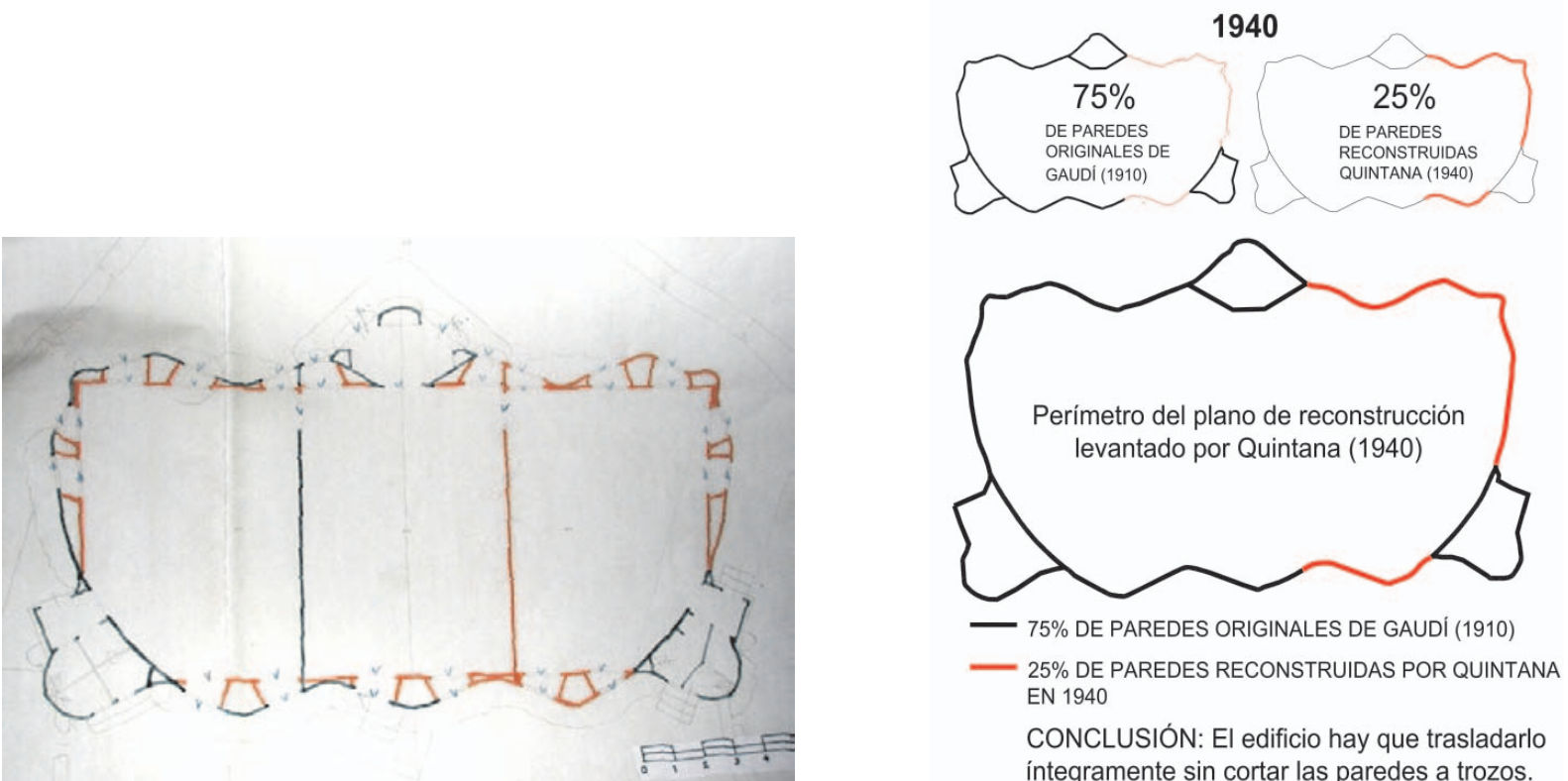

CONCLUSIÓN: El edificio hay que trasladarlo integramente sin cortar las paredes a trozos.

Fig.I.7. a) Fotografia de la planta de la reconstrucción de las Escuelas de Quintana, donde indica, en rojo, la parte reconstruida, añadiendo el recuadrado interior de las aulas; b) Esquema sobre el plano de la planta de las Escuelas levantado por Quintana (1940), indicando, en rojo, la parte reconstruida (sin el recuadrado de las aulas), y, en negro, la parte original de Gaudi, donde puede medirse que lo que queda original es el 75\% y lo rehecho es del 25\%, después de los dos incendios (Foto S. Calvo).

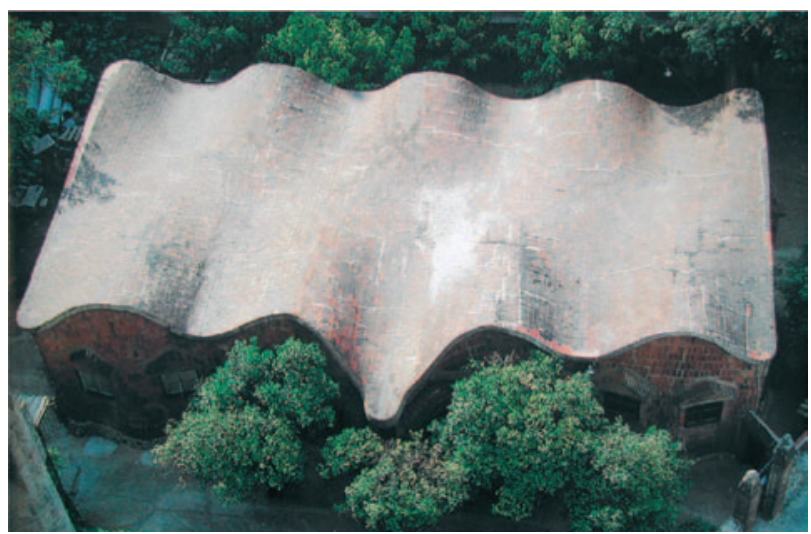

Fig. I.8. Vista en planta de la cubierta de las Escuelas de Gaudi, una vez reconstruidas por Quintana en 1938 y 1940 , alterando sustancialmente su terminación formal original de Gaudi, muerto en 1926, al quitar la cresta central que dividía la cubierta en dos faldones, convirtiéndola en una cubierta a una sola agua vertiendo a lados distintos alternativamente.

original de Gaudí consistía en un edificio de esbeltas paredes onduladas, determinadas por conoides contrapuestos que, por su curvatura, adquirían suficiente resistencia para soportar las cargas de la cubierta. Junto a ello una cubierta con muros pares de "construcción tradicional", si bien de geometría muy original, con conoides contrapuestos entre sí apoyados sobre viguetas de madera, las cuales, a su vez, descansaban sobre una viga central que descargaba en tres soportes (Fig.I.6.a).

Esta original cubierta desde el punto de vista formal, presentaba distintas secciones: horizontal, si se cortaba por el eje entre ondas, e inclinada a izquierda o a derecha, si se cortaba por un eje de máxima ondulación, incorporando además una cumbrera central (Fig.I.6.b).

Quintana, después de la devastación del incendio y con la concepción de provisionalidad de la edificación, aconsejó reconstruir la cubierta y reforzar las paredes recuadrando las aulas, lo que quedó expuesto en el plano de reconstrucción levantado por este Arquitecto en "color rojo" (Fig.I.7.a).

Del análisis de este plano, considerando sólo el perímetro ondulado de las paredes (sin el recuadrado), se deduce que Quintana reconstruyó el 25\% de paredes permaneciendo en pie el $75 \%$ de paredes originales de Gaudí, lo que justificaría posteriormente, el traslado del edificio de una pieza, en lugar de trocearlo (Fig.I.7.b).

Quintana, en la reconstrucción de la cubierta de Gaudí, no dispuso la cumbrera central que la dividía en dos faldones, sino que dio continuidad a los conoides de ambos lados, transformándola en una cubierta de dos a una sola agua, que, con sus ondulaciones alternativas, la vertía a las fachadas contrapuestas (Fig.I.8). 

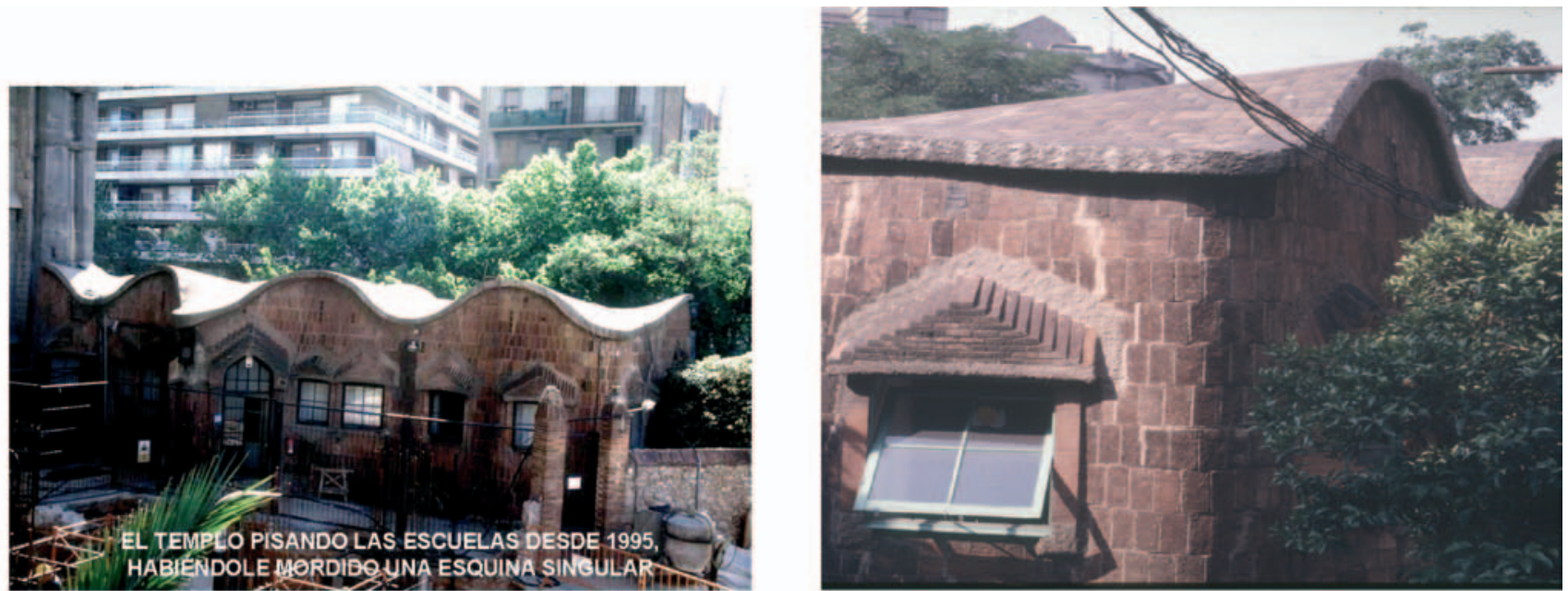

Fig.I.9. a) Vista de las Escuelas con el pilar del Templo pisándolas por su esquina noreste; b) Encuentro de las fachadas larga y corta, redondeado de la esquina norte del edificio derruida en 1995, al ubicar el pilar de la nave del Templo, pisando las Escuelas.

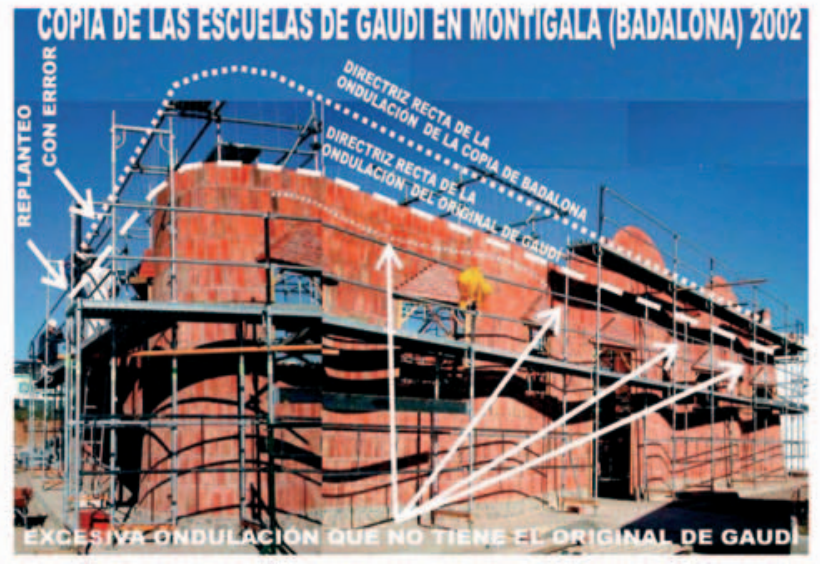

Fig. I.10: Copia de las Escuelas de Gaudí en Montigalá, donde se aprecia claramente, por la sombra del andamio sobre la pared, que la ondulación de la misma supera ampliamente por arriba de los frontones de los huecos, llegando a "morder", por tanto, la propia ondulación de la cubierta, en contra del original de Gaudi.

Durante la progresión de las obras de la Sagrada Familia y acercándose el año 2000, fecha en que se celebró una misa solemne para conmemorar la terminación de la nave central del Templo, se tomaron apresuradamente decisiones respecto del crecimiento de la nave del Templo hacia el Pórtico frontal de la Gloria, cuya ubicación coincidía precisamente en el mismo espacio físico de uno de los laterales de las Escuelas, lo que implicó el recorte de la esquina noreste de las Escuelas en 2 trozos en 1995.

Desde entonces el Templo estuvo "pisando" las Escuelas, hasta el año 2002, año del 150 Aniversario del nacimiento de Gaudí, cuando se reconstruyó el edificio en otro lugar (Fig.I.9.a).

La esquina que ocupó el pilar del Templo, fue recortada y sus trozos se mantuvieron "aparcados" en las inmediaciones (después de armarlos con mallazos y gunitarlos por su trasdós), a la espera de utilizarse en la reconstrucción, aunque al final no se utilizaron (Fig.I.9.b).

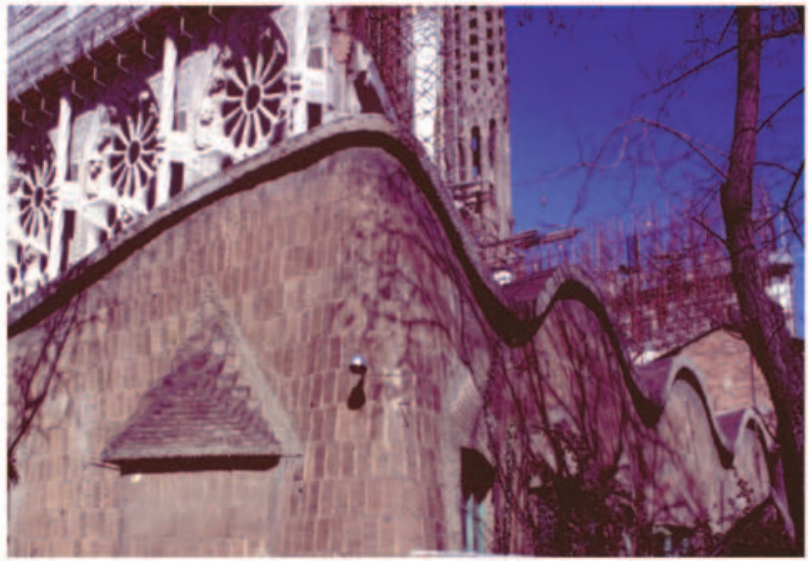

Fig. I.11: La falta de coincidencia entre el original y su copia ya podía verse perfectamente en las fotos publicadas en La Vanguardia el día 8/02/ 2002, cuando se comentaba el debate mantenido en el Ateneo sobre las Escuelas del día 6 de febrero (Foto Adell).

Al acercarse el año 2002, se decidió hacer una copia de las Escuelas en Montigalá (Badalona) que sirviera de aprendizaje para la reconstrucción posterior del original.

Si analizamos en profundidad la copia de las Escuelas realizada, podrá observarse que la misma tiene sustanciales variaciones respecto del original, lo que la convierte en un subproducto de la obra de Gaudí, dado que ni siquiera queriendo ser fidedigna, lo ha logrado conseguir, a la vista del importante error de replanteo que manifiesta su ejecución, con respecto a la obra original de Gaudí (Fig. I.10).

Cabe decir, pues, que la copia realizada en Badalona, se aleja bastante del original real, hasta el punto de que sería imposible casar el conjunto de los trozos originales del edificio de Gaudí con los trozos del edificio copiado, que es lo que teóricamente se plantearía hacer delante de la fachada de la $\mathrm{Pa}$ sión. Teoría que permitiría, posteriormente, adaptar los recortes que van a hacerse del original hasta su nueva ubicación (Fig. I.11). 
Como puede apreciarse también en la figura I.1.a., el replanteo de la curvatura de la copia, no se corresponde con el original de Gaudí, que arranca a nivel del apoyo de las ondas de la cubierta por su parte inferior, en lugar de la parte superior de las mismas.

A lo largo de 93 años de la existencia de las Escuelas, y después de los incendios durante la guerra y la reconstrucción que soportó el edificio, apenas se actuó sobre él como no fuera para impermeabilizar alguna que otra gotera, o para recortarle la esquina en 1995.

\section{PROPUESTA DE TRASLADO POR FLOTACIÓNALA PLAZA COLINDANTE DE LA SAGRADAFAMILIA(J.M.} Adell, 1998)

Evidenciado que dentro del solar de la Sagrada Familia no tenía “cabida física adecuada" el edificio de las Escuelas trasladado, por lo menos desde un punto de vista de su apreciación visual como obra individual, con el mínimo espacio circundante y con un fondo apropiado para su contemplación, no quedaba otra posibilidad que pensar en buscar un lugar en las inmediaciones de dicho solar (Fig.II.1).

Bajo estos planteamientos, el chaflán de la esquina de las calles Mallorca y Sardenya, inmediato a la ubicación original de las Escuelas, se perfilaba como el lugar más idóneo para su nueva ubicación, aprovechando precisamente el entorno arbolado que permitirá enaltecer tan singular obra de Gaudí. Obra que ha pasado desapercibida hasta ahora, como si se tratara de un enano a los pies de un gigante, lo que se lograba evitar totalmente en la nueva ubicación, al quedar envuelta de vegetación a su alrededor.

Estudiando detenidamente la organización en planta del edificio de las Escuelas y el reparto de cargas que el mismo ofrece, que responde a una simetría perfecta en el eje transversal y a un aproximado equilibrio en el longitudinal, si consideramos el extremo sobresaliente de la fachada principal respecto de la ubicación de los aseos junto a la fachada posterior, se ha inventado un sistema específico de traslado para salvar las Escuelas de Gaudí, que nace de la ligereza propia de sus paredes y cubierta, y del reparto equilibrado de sus masas, función de su planta de edificación.

Por todo ello, se ha patentado un Sistema específicamente idóneo para trasladar las Escuelas de Gaudí por flotación (Fig.II.2):

"El Sistema consiste en aislar la cimentación del edificio con respecto al terreno que lo sustenta, establecer bajo ella una plataforma adecuadamente configurada para sustentar el edificio, por flotación, sobre una masa líquida y establecer un vaso o canalización entre las posiciones inicial y final para el edificio, llenando dicha canalización con el líquido apropiado (agua natural o de mar...) para que el edificio

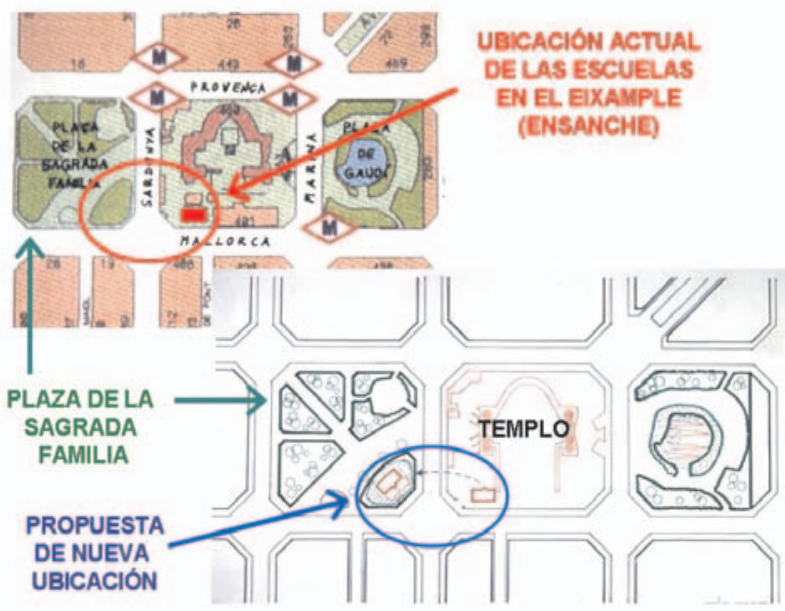

Fig.II.1. Propuesta de nueva ubicación de las Escuelas en la Plaza de la Sagrada Familia por J.M. Adell

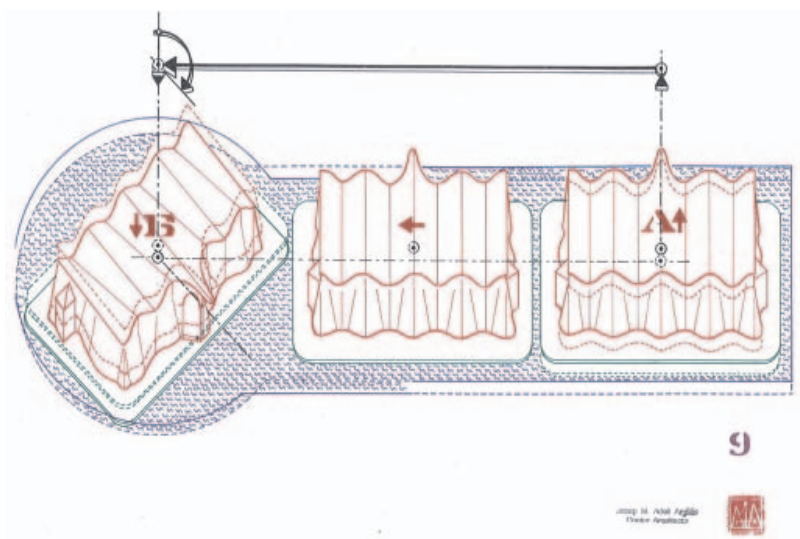

Fig. II.2: Gráfico que expresa el "Sistema para movilización y desplazamiento de edificios" inventado especificamente para trasladar las Escuelas de Gaudí, en razón de la ligereza y equilibrio de masas de la obra de Gaudi, patentado por J.M. Adell en 1998, ante la falta de interés existente en el desplazamiento.

sufra una elevación, efectúe seguidamente un desplazamiento lineal o giratorio del mismo, según se desee, y procediendo finalmente a eliminar el líquido, para lograr que se produzca su automático descenso en el nuevo lugar y posicionamiento previsto para el edificio".

Las ventajas del Sistema de movilización de las Escuelas por flotación, son:

- Es un procedimiento ecológico y económico que no consume ningún tipo de energía.

- Logra desplazar el edificio sin técnicas complejas y con infinitas posiciones de ajuste.

- $\quad$ Permite una absoluta fiabilidad en el nivelado de elevación y movimiento del edificio.

- Es muy idóneo para cuando hay que cambiar de posición, orientación y cota de nivel.

- $\quad$ No se requiere ni nivelar, ni hormigonar, ni reforzar el terreno sobre el que se desplaza

- Requiere el mismo coste de refuerzo de cimentación que cualquier otro método usado. 


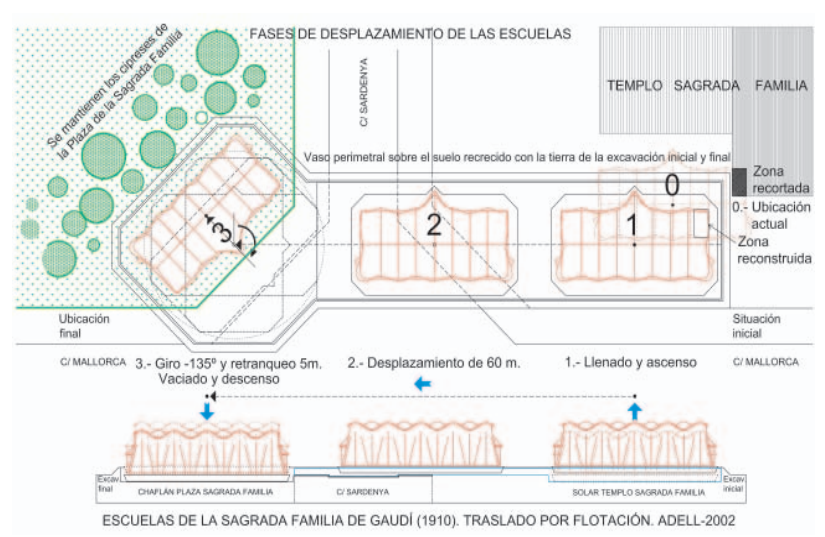

Fig. II.3. 1) Inicio del desplazamiento de las Escuelas, por flotación, desde el solar de la Sagrada Familia; 2) Situación intermedia de las Escuelas en su desplazamiento por flotación cruzando la calle Sardenya entre el solar de la Sagrada Familia y la Plaza del mismo nombre. 3) Situación final de las Escuelas, dentro del jardín del chaflán de la Sagrada Familia donde han de girar $-135^{\circ}$ para orientarse al chaflán, y adentrarse unos $5 \mathrm{~m}$ hacia la zona ajardinada, para encontrar su posición definitiva.

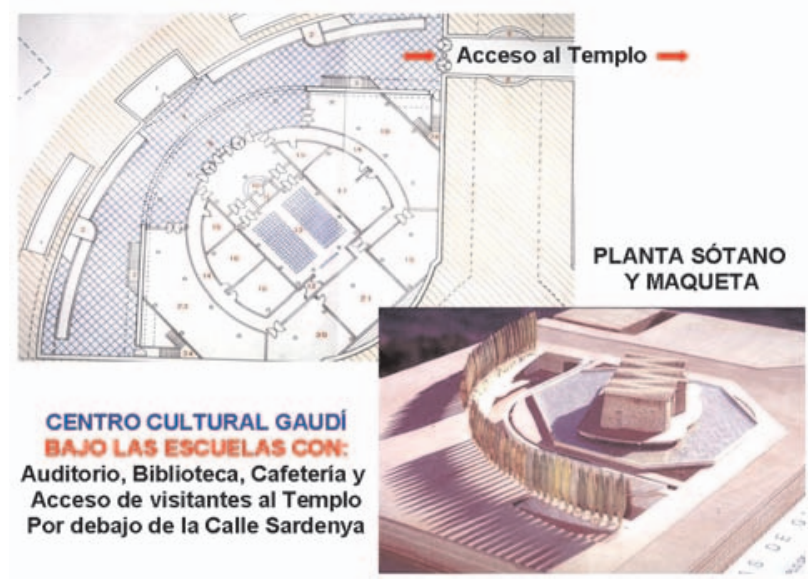

Fig. II.4: Planta sótano y maqueta a nivel de la Plaza, de la nueva ubicación propuesta para las Escuelas, con el Centro Gaudí y el acceso subterráneo al Templo de la Sagrada Familia, desde la plaza colindante.

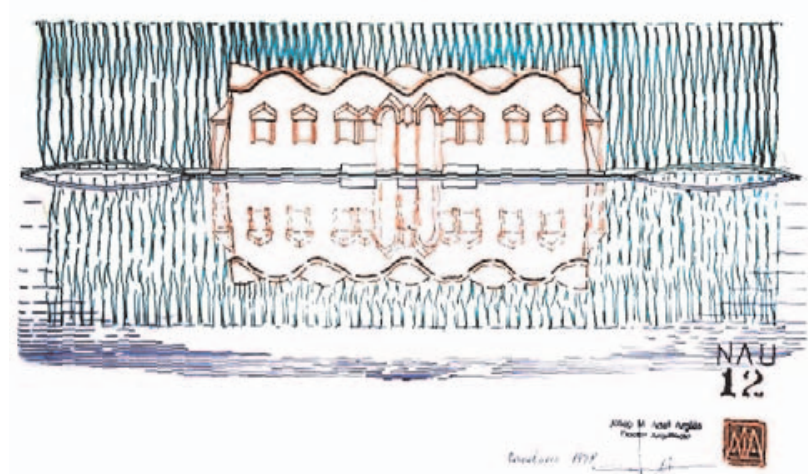

Fig. II.5: Gráfico de la ubicación definitiva de las Escuelas en la plaza colindante (propuesta J.M. Adell).

Se diferencian 3 fases de desplazamiento de las Escuelas hasta su nueva ubicación (Fig.II.3.):

Fase $1^{\text {a }}$ : consiste en el llenado del vaso inicial donde están originalmente ubicadas las Escuelas, para lograr el ascenso por flotación del edificio hasta el nivel deseado en función del desplazamiento fijado (Fig.II.3-1).
Fase $2^{a}$ : consiste en desplazar el edificio por flotación una distancia de unos $60 \mathrm{~m}$, pasando sin tocarlo, por encima de parte del solar de la Sagrada Familia, por encima de las aceras y calzada de la calle Sardenya, hasta adentrarse por encima del jardín de la plaza de la Sagrada Familia. En esta fase se habrá controlado que el nivel de flotación de la embarcación que constituye el edificio, sobrepasa, sobradamente, todos los altibajos que pudiera haber, como los bordillos de las aceras, etc. (Fig.II.3-2.).

Fase $3^{\mathrm{a}}$ : consiste en un giro de $-135^{\circ}$ de la embarcación de las Escuelas, y su posterior retranqueo, unos $5 \mathrm{~m}$, hasta adentrarse en el interior del perímetro achaflanado de la zona ajardinada de la Plaza de la Sagrada Familia, que da frente a la esquina entre las calles Mallorca y Sardenya (Fig.II.3-3.).

La nueva propuesta de ubicación se organizaba sobre el nuevo "Centro Cultural Gaudí" bajo las Escuelas de la Sagrada Familia dispuesto en la planta sótano y con entrada directa bajo la c/ Sardenya para visitar el Templo (Fig.II.4).

Este centro resolvía la problemática que representa la avalancha de turismo con colas que interrumpen toda la calle para visitar la S.F. Planteaba un salón de actos enterrado, una biblioteca, salas de reuniones, cafetería y servicios, y varias plantas de aparcamiento (tanto de automóviles como de autobuses), y todo ello sin entorpecer el espacio urbano del ensanche que actualmente está totalmente colmatado.

Las escuelas una vez trasladadas podrían reutilizarse por la S.F. para la librería especializada en Gaudí ofreciéndose dos alternativas en su disposición, con el fondo ajardinado de la plaza de la Sagrada Familia:

- $\quad$ o bien, sobre una zona de césped que la envolviera con el fondo de los cipreses,

- o bien, sobre un lago artificial como recuerdo de su traslado por flotación que se salvaría con un par de puentes de acceso a las escuelas (Fig.II.5).

\section{DESPEDAZADO Y RECONSTRUCCIÓN REALIZA- DA POR J.C.T. (2002)}

La Junta Constructora del Templo (J.C.T.) de la Sagrada Familia, no aceptó trasladar el edificio fuera de su recinto, hasta la plaza colindante nada más cruzar la calle, y decidió reubicar las Escuelas delante de la Fachada de la Pasión, argumentando la precariedad de la edificación, y justificando así su "imposible salvación de una pieza" (Fig.III.1).

En contra de toda la normativa legal, ya que el edificio estaba catalogado de MONUMENTO HISTÓRICO-ARTÍSTICO DE CARÁCTER NACIONAL por Decreto 1794/1969 del B.O.E. 20-VIII.1969, siendo parte del CATÁLOGO DEL PA- 
TRIMONIO ARQUITECTÓNICO DE BARCELONA en su edición de 1987 (Categoría A, Capítulo I), la Junta Constructora del Templo de la Sagrada Familia, logró el beneplácito de las Administraciones, Central y Autonómica, para despedazar el edificio y supuestamente volverlo a recomponer empleando todos los trozos.

La J.C.T. decidió recortar las Escuelas en trozos para reubicarlos a una distancia de no más de $30 \mathrm{~m}$ de la situación original en su nueva posición, giradas $90^{\circ}$ respecto de su posición inicial, mostrando su frente hacia la calle Sardenya. Dada la ligera pendiente del solar y la calle, fue necesario rellenar un terraplén para crear un plano horizontal. De tal manera que el cambio de ubicación por trozos, sólo requería de una grúa con la pluma de longitud adecuada, para que dispuesta en la zona intermedia, pudiera levantar y posar posteriormente, los trozos del despiece (Fig.III.2).

En el año 2002, el traslado que planteó hacer la Junta Constructora de la Sagrada Familia por trozos y apedazado, después de justificar lo injustificable empleando para ello mediciones manifiestamente (o maliciosamente) erróneas, era solamente una "manera de hablar", puesto que la intención explícita consistía en hacer una copia "prácticamente" nueva del original, para lo que ya había experimentado el proceso

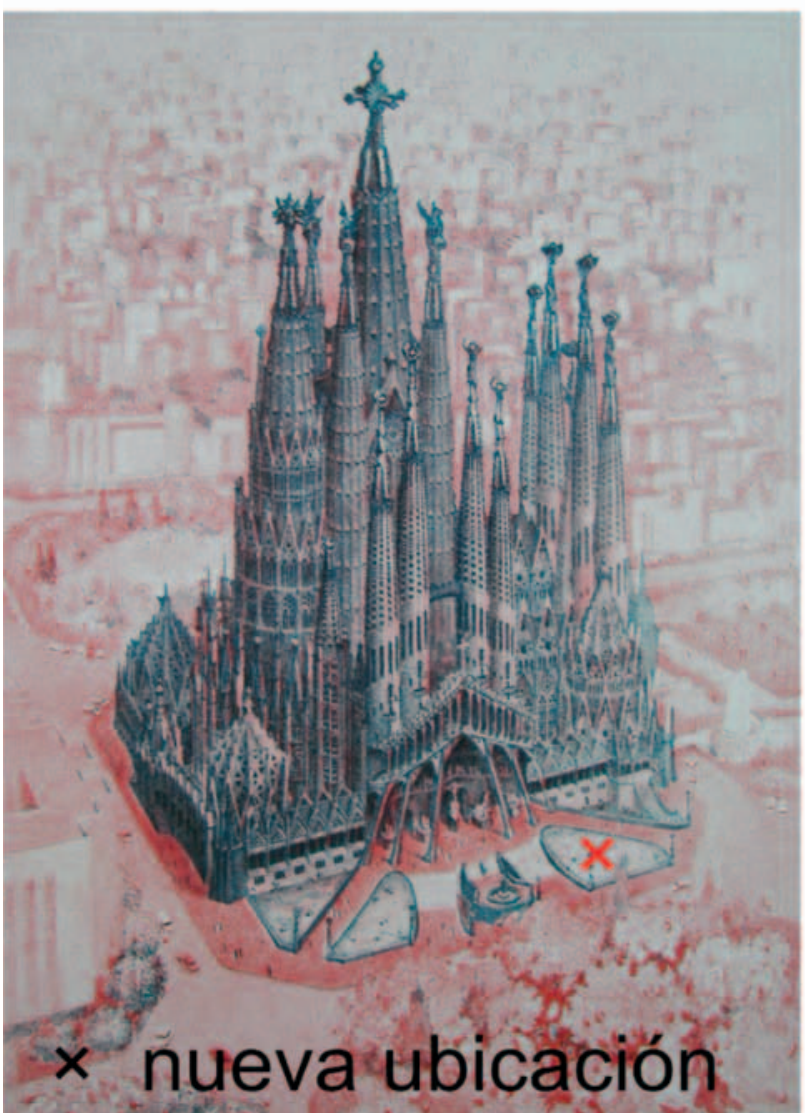

Fig. III.1: Dibujo que muestra el Templo de la Sagrada Familia terminado, con sus escalinatas y rampas, mostrando que no existe espacio apropiado para las Escuelas de Gaudi en el mismo solar del Templojunto a la fachada de la Pasión, indicándose con una cruz, la nueva ubicación.

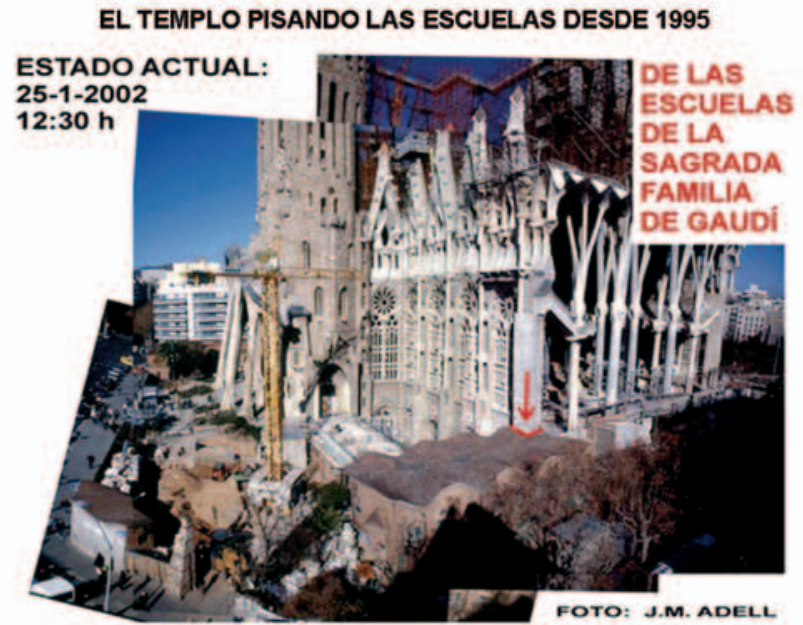

Fig. III.2. Fotografía que muestra cómo el Templo "pisa" la esquina norte de las Escuelas, desde que en 1995 se construyó el pórtico correspondiente dentro de ellas.
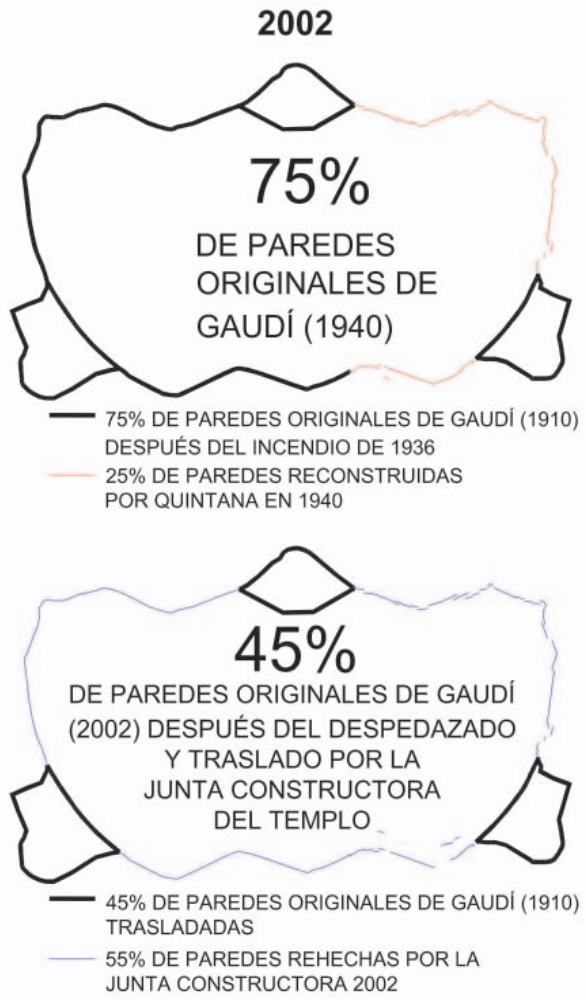

Fig.III.3. Disminución del $30 \%$ de porcentaje de paredes originales de Gaudi, pasando del $75 \%$ al $45 \%$ después del traslado por la J.C.T. y quedando sólo los 3 pedazos con sus accesos incorporados.

con la copia realizada en Montigalá, y mantuvo, al final, sólo tres trozos, los más complejos de copiar, además de los huecos que se recortaron y se fijaron sobre la obra de nueva factura, y ni siquiera se emplearon los que en su día se recortaron y guardaron, cuando se levantó el pilar de la nave, "pisando" las Escuelas en 1995.

El resultado del despedazado y supuesto posterior apedazado de las paredes de las Escuelas de la Sagrada Familia, pasó de tener el $75 \%$ de paredes originales de Gaudí (después de que- 


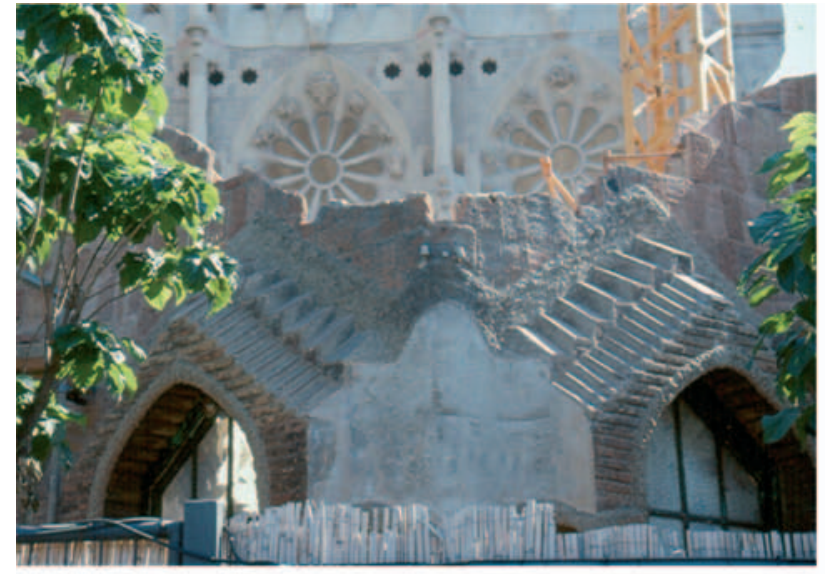

Fig.III.4. Pedazo con la puerta principal dispuesto en su nueva ubicación para encajarlo con las nuevas paredes tabicadas.

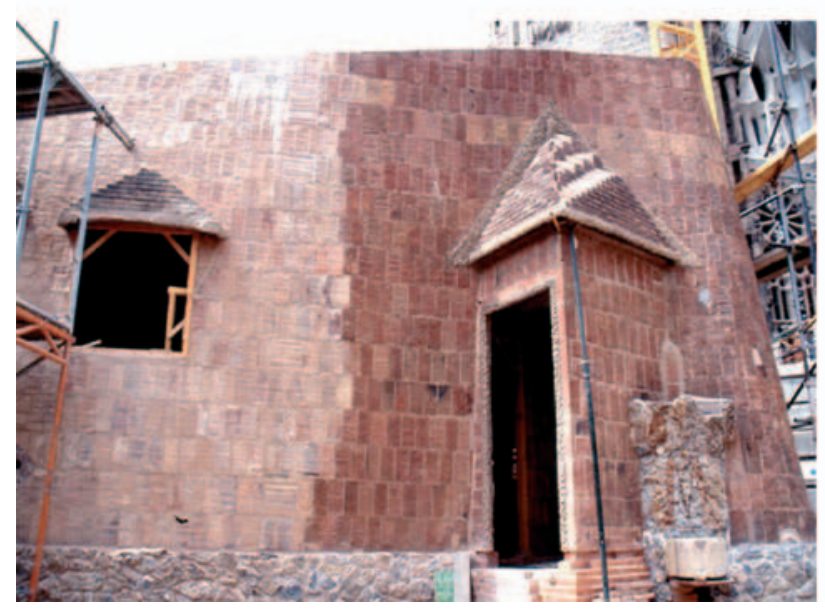

Fig.III.5. Visible apedazado entre el pedazo de la esquina con la puerta y las nuevas paredes tabicadas.

marse un $25 \%$ durante la guerra), a quedar ya sólo un $45 \%$ de paredes originales de Gaudí en la edificación actual, después del traslado por trozos, además de que la ondulación de las nuevas paredes construidas, como ya se ha comentado, no coinciden con el original, lo que no puede ya apreciarse, dado que los 3 trozos salvados (la puerta principal y las dos laterales), sobresalen del conjunto de la ondulación hecha de nuevo (Fig.III.3).

Se puede apreciar con claridad, en las nuevas Escuelas, por el cambio de color de los ladrillos originales, que eran mucho más rojizos que los empleados en la realización de la copia, cómo se distingue el "cosido" entre las partes viejas y nuevas del edificio, a ambos lados de la puerta principal original (Fig.III.4), así como también a ambos lados de los dos cuerpos con puertas de acceso por las esquinas (Fig.III.5).

La construcción de la ondulación del conjunto de las paredes de la fachada, tiene el mismo defecto que ya se denunció en su día en el periódico La Vanguardia, cuando se hizo la copia

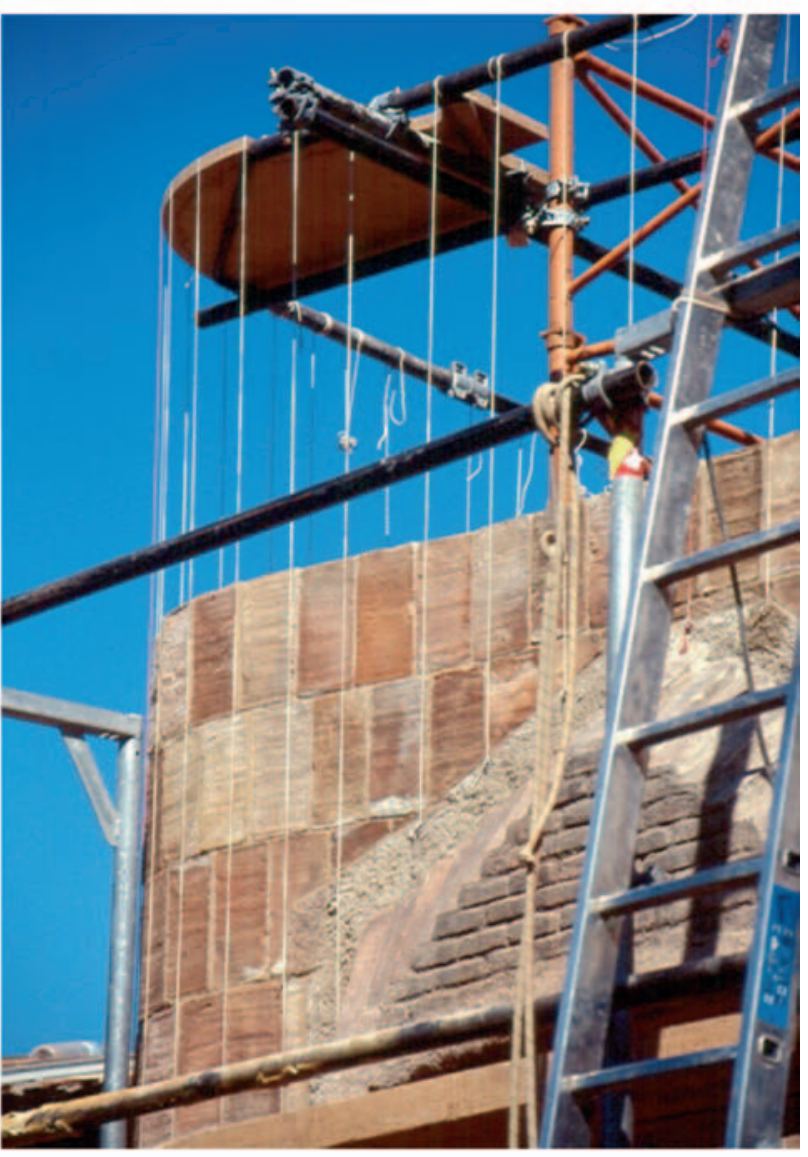

Fig.III.6. Ejecución de esquinas con paredes tabicadas totalmente nuevas, y con error de curvatura.

preparatoria para el despedazado y reconstrucción del original, ya que la directriz recta de la ondulación de las nuevas Escuelas de Gaudí en la Sagrada Familia, se ha hecho 1,20 m más arriba del original, empleando para ello múltiples hilos guía (Fig.III.6), por encima de las ondas de la cubierta, en lugar de por debajo de las mismas (ver Fig.I.9.b, y Fig.I.11 del original) y como muestra también Molema en el gráfico de su libro.

Respecto a la cubierta, la J.C.T. en ningún momento aceptó que la obra de las Escuelas constituyeran para Gaudí una fase de aprendizaje para la posterior realización de los paraboloides e hiperboloides que cierran la nave del Templo, aunque dispuestos en vertical, y no quiso negar la evidencia documental de que se trataba de una cubierta a dos aguas, con una cumbrera central, por lo que se hizo nuevamente la cubierta, a la manera de la reconstruida por Quintana después de incendiarse.

La ondulación de la cubierta con planos curvos que alternativamente vierten aguas a las fachadas opuestas, se logra con tablones de madera apoyados en dichas fachadas y en la viga central. Sobre ellos se ha dispuesto una primera hoja de "tobas" de baldosas cuadradas con la cara vista mirando ha- 

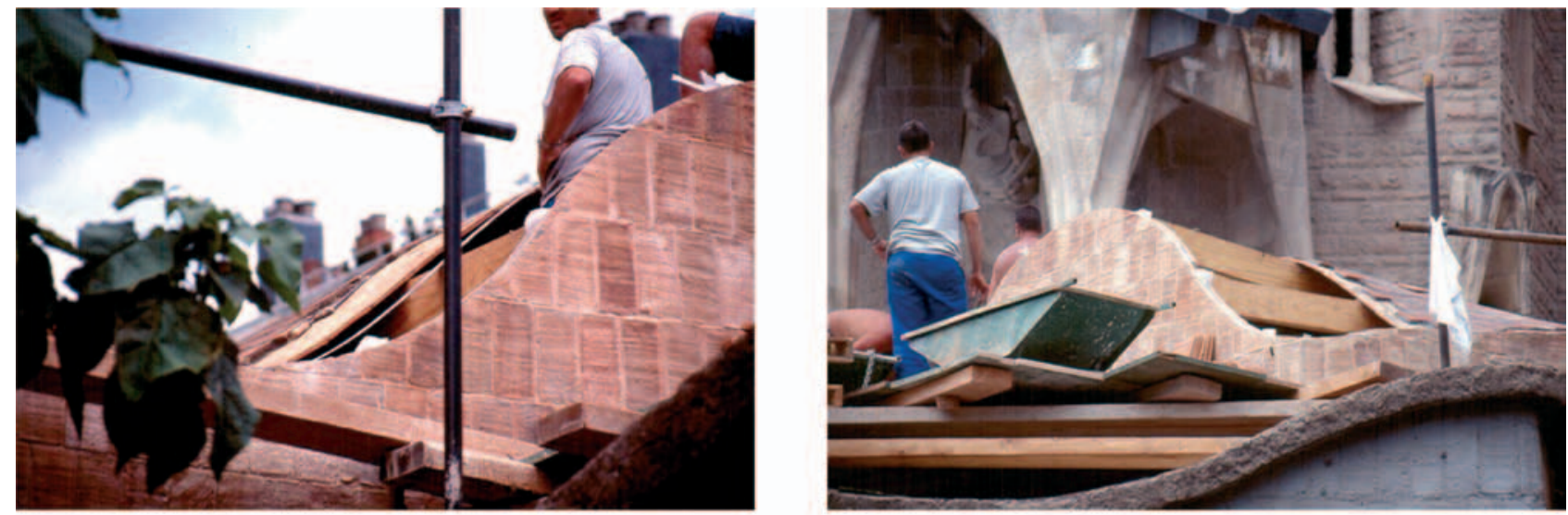

Fig.III.7.a) Ejecución del tablero de cubierta con baldosa cerámica empleando una pletina guía; b) Ejecución de la segunda hoja previa disposición de un mallazo intermedio.
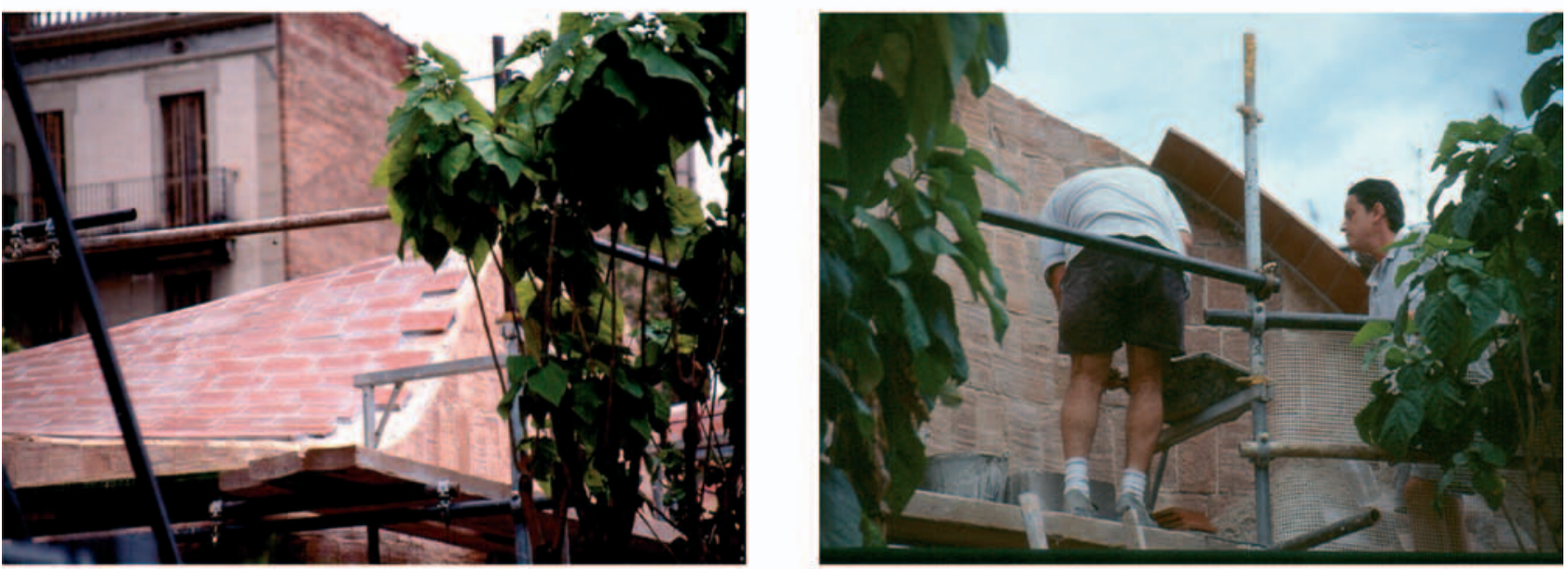

Fig.III.8.a) Acabado exterior de la cubierta con baldosín catalán; b) Vuelo del baldosín catalán para conformar el alero.

cia el interior de las Escuelas, ayudándose de una pletina metálica a modo de guía, por su capacidad de adaptarse a la curvatura de la ondulación que varía con cada nueva hilada (Fig.III.7.a,b).

Sobre esta primera "volta" se ha dispuesto un mallazo tomado con mortero de cemento, y, sobre éste, el conocido baldosín catalán, por su impermeabilidad, con el formato del ladri1lo, aunque de menor grueso. En los extremos de apoyo de la cubierta sobre los muros de ambas fachadas largas, se ha volado dicho baldosín generando una onda capaz de desaguar las aguas, alejándolas del plano de fachada (Fig.III.8.a,b)

La réplica, una vez completada, puede apreciarse desde la calle (a través de una valla metálica poco densa) con el fondo de la portada de la Pasión y la nave del Templo (Fig.III.9).

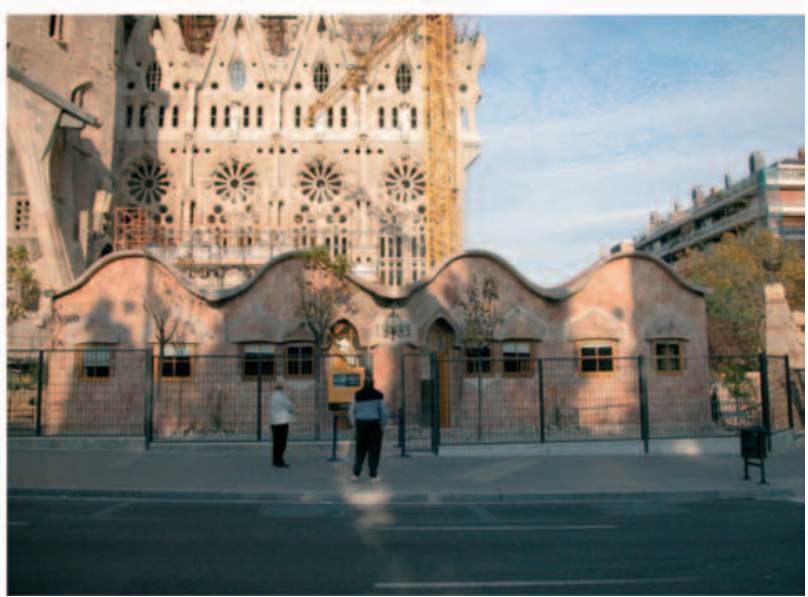

Fig.III.9. Vista conjunta de las Escuelas a los pies de la portada de la Pasión y con la nave del Templo al fondo. 

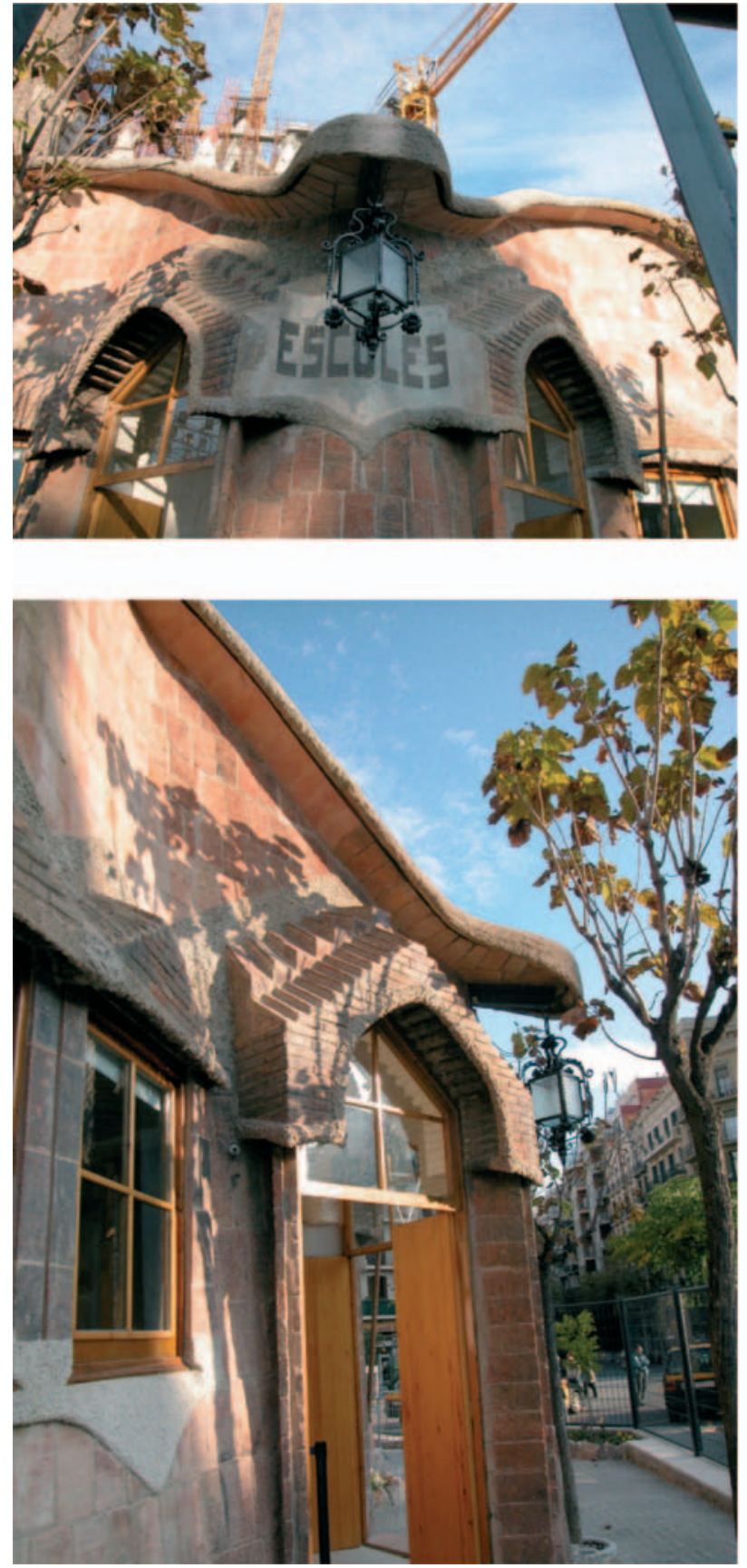

Fig.III.10. a) Detalle del acabado de la portada principal con su visible apedazado a ambos lados; b) Vista lateral de la puerta anterior, donde nuevamente se aprecia el cambio de color en el apedazado.

En una observación próxima de la obra, se muestra claramente el apedazado de la Portada principal con el anagrama de las "Escoles" originales, de la ondulación lateral por el cambio del color rojo oscuro de los ladrillos originales, frente a los nuevos, de color mucho más pardo (Fig.III.10.a,b).

En una vista en ángulo desde la calle, de cualquiera de las dos esquinas que pueden apreciarse las Escuelas, se observa claramente cómo todas las paredes onduladas son nuevas (ladrillos pardos), por el cambio de color que manifiestan en su encuentro con las puertas de las esquinas posteriores del edificio (ladrillos más rojos) (Fig.III.11).

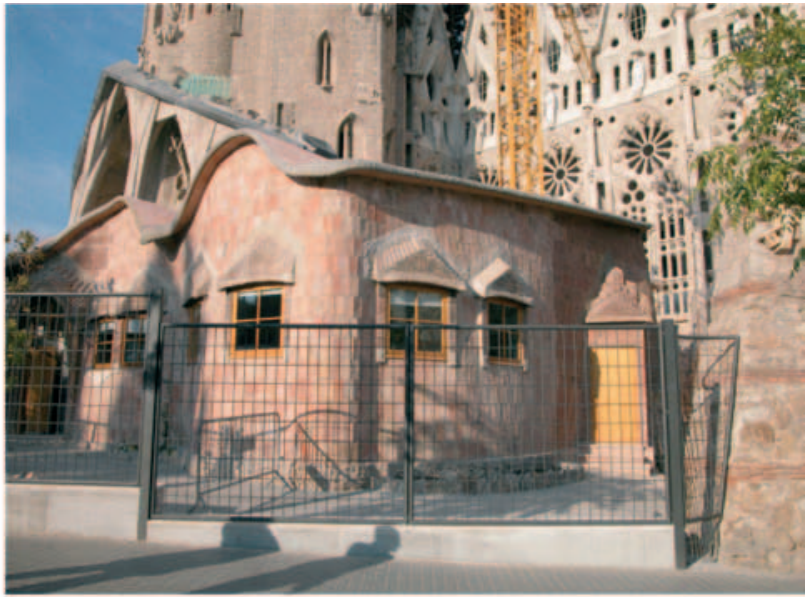

Fig.III.11. Esquina de las Escuelas totalmente nueva, que se apedaza visiblemente con el pedazo de esquina posterior con puerta.

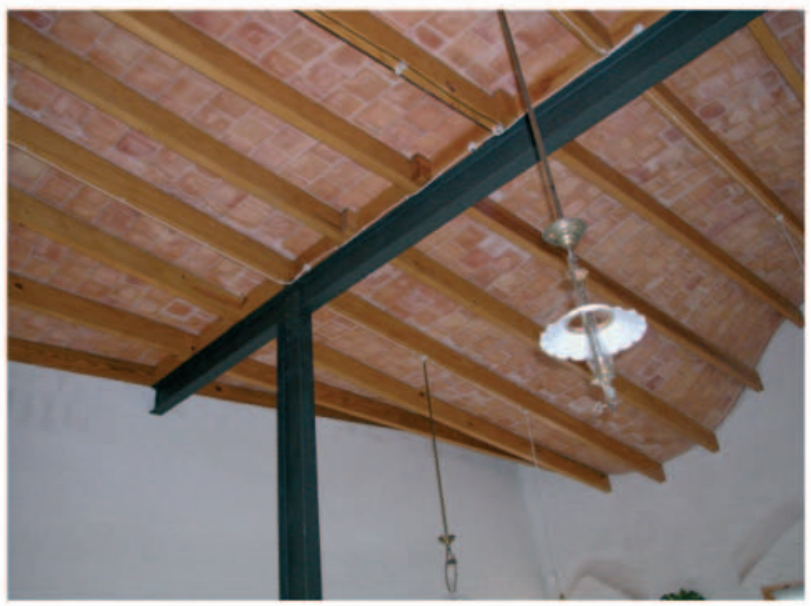

Fig.III.12. Vista de la cubierta por su interior, donde se aprecia la discontinuidad entre los tablones de apoyo sobre la viga, y la baldosa empleada para dejar un acabado visto del techo ondulado.

Por el interior de las Escuelas, pueden apreciarse los tablones empleados para crear la ondulación, que tienen la longitud de la mitad del vacío de las aulas, apoyándose en la viga central, sin tener, por tanto, una continuidad física (aunque virtual), en contra de lo dibujado reiteradamente en múltiples publicaciones, lo que inevitablemente volverá a partir en dos el plano de la cubierta actual con el tiempo, generando filtraciones de agua (Fig.III.12).

\section{PROPUESTA DE CUBIERTA CON LA TÉCNICA DE DIESTE (J.M. Adell)}

Retomemos a continuación lo que se publicó en el Monográfico de la Revista Informes de la Construcción (1992) sobre "La Fábrica Armada" (Fig.IV.1).

En el artículo del Monográfico titulado "Las bóvedas de la Atlántida”, este autor hacía una comparación formal entre 


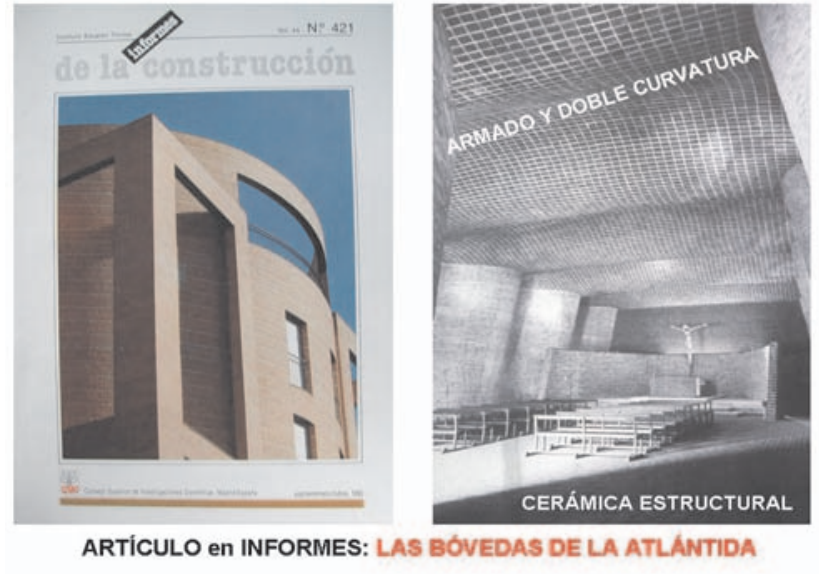

Fig.IV.1. Portada de la Revista Informes de la Construcción n $n^{\circ} 421$ (1992) Monográfico sobre "La Fábrica Armada", y que presenta la obra de cerámica estructural de Dieste.

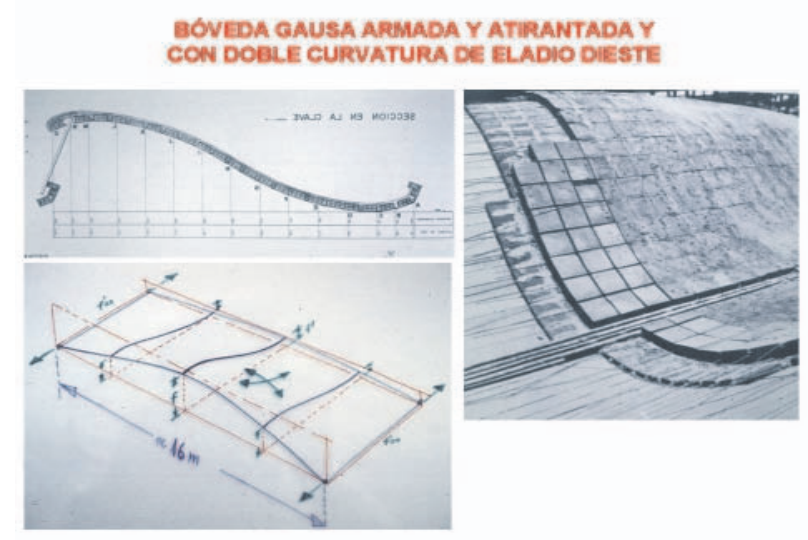

Fig.IV.3. Bóveda "gausa" inventada por Dieste con la particularidad de su doble curvatura variable, y de incorporar armado bidireccional homogéneo, además de atirantados localizables.

las Escuelas de la Sagrada Familia de Gaudí (Barcelona, 1909), y la Iglesia de la Atlántida de Dieste (Uruguay, 1952), comprobando que la muy distinta escala de ambas obras, se correspondía con las distintas prestaciones técnicas que el armado permitía en las cubiertas de doble curvatura de Dieste frente a las de una sola curvatura y sin armar de Gaudí (Fig.IV.2).

Dieste inventó lo que él denominó "la bóveda gausa", consistente en una cubierta de doble curvatura, variando la magnitud de la ondulación en cada una de sus dos direcciones ortogonales. Su originalidad estaba en que el peso de la misma no influía en la luz del vano a cubrir y que el armado soportaba las flexiones que se producían en su conjunto (Fig.IV.3).

Dieste pudo incorporar un armado homogéneo en la fábrica, gracias a disponer las piezas en retícula para dejar líneas de armado ortogonales entre las piezas cerámicas, las cuales podía, a su vez, reforzar con atirantados donde le fuera preciso. Con su nueva tecnología de cerámica armada, el Arquitecto uruguayo superó la luz de $5 \mathrm{~m}$ de las Escuelas de Gaudí

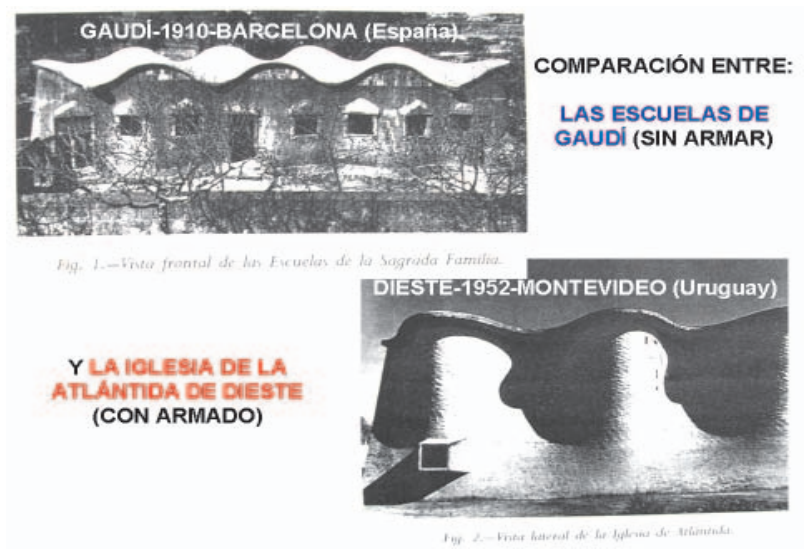

Fig.IV.2. Contraste formal entre las Escuelas de la Sagrada Familia de Gaudí, sin armar, y la Iglesia de la Atlántida de Dieste, con armado, con independencia de la escala.

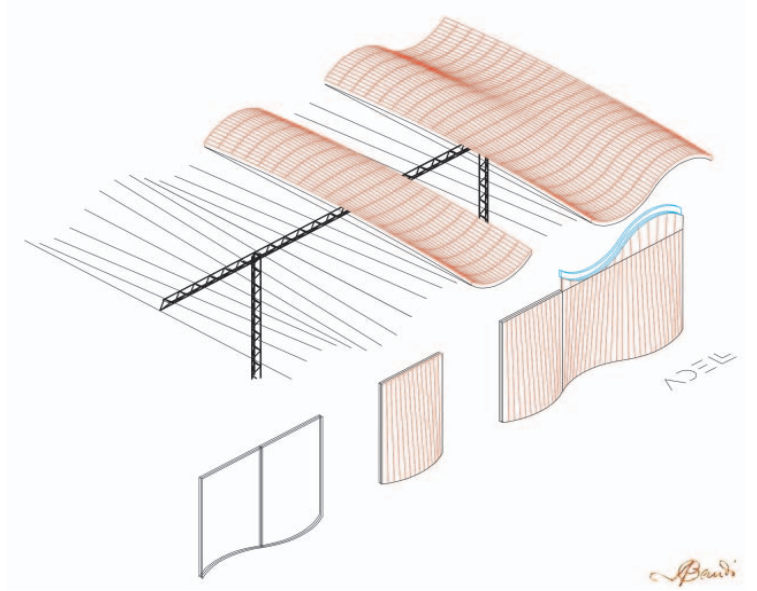

Fig.IV.4. Planteamiento de una nueva tipología de cubierta atirantada para las Escuelas de la Sagrada Familia, resuelta con doble curvatura (Gaudi-Dieste-Adell),

(entre fachada y viga central), llegando a los 16m en las bóvedas de la Iglesia de la Atlántida.

El artículo realizado en 1992, dio pie, a este autor, a un dilatado diálogo con el Patronato del Templo de la Sagrada Familia, haciéndoles ver la originalidad de la obra de Gaudí y ofreciéndoles la colaboración para el desplazamiento integral de las Escuelas, lo que, como se ha visto en última instancia, no llegó a prosperar.

Este autor, junto con Dieste, propusieron transformar la cubierta incendiada de Gaudí por otra nueva capaz de soportar el fuego y de evitar incluso, en una segunda variante, la estructura de pilares y vigas que discurren como eje central de la nave de las Escuelas.

Para ello desarrollaron conjuntamente un nuevo tipo de bóveda adaptada a la de conoides de Gaudí para las Escuelas, pero dándole una ligera doble curvatura en el sentido transversal del edificio, lo que generaba unos empujes sobre los apoyos de los muros que eran absorbidos y contrarrestados por una sucesión de tirantes dispuestos en la misma posición de los actuales tablones de apoyo (Fig.IV.4). 


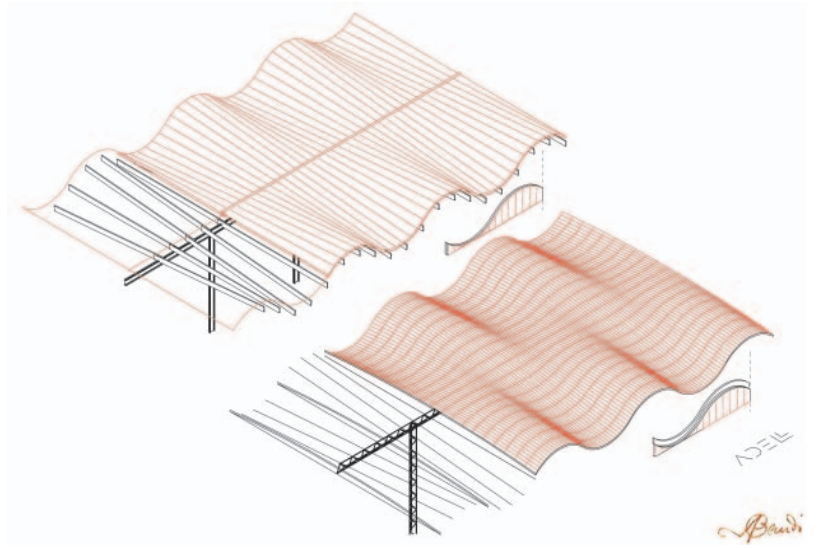

Fig.IV.5. Comparación de la cubierta original de Gaudí con su cumbrera central, con la de doble curvatura atirantada que evita el remanso del agua.

sin cumbrera central

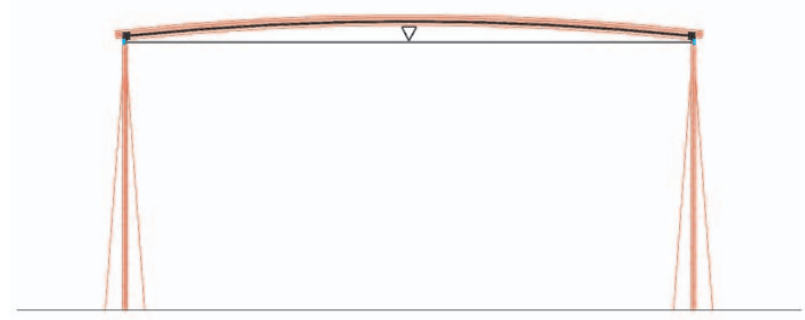

\section{SECCIONES TRANSVERSALES DE LA CUBIERTA DE DOBLE CURVATURA PROPUESTA POR J.M. ADELL \\ - por eje entre ondas \\ - por máxima ondulación \\ (sin cumbrera central)}

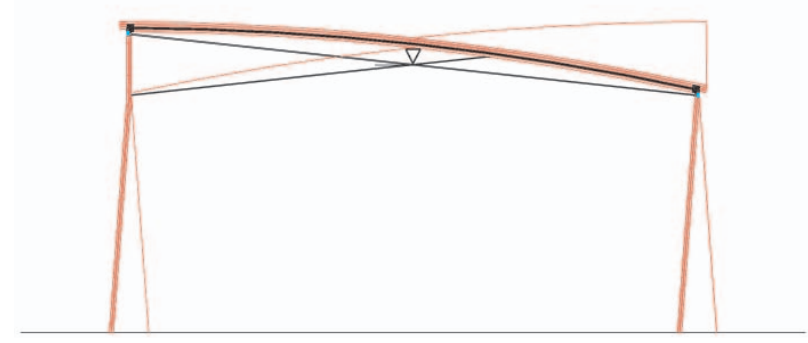

Fig.IV.6. Secciones transversales de la nueva cubierta Gaudi-Dieste-Adell, incorporando la viga central entre la curvatura y los tirantes que eliminan sus empujes, apoyándose en los soportes y volando en ménsula hacia las fachadas.

El resultado obtenido con esta transformación técnica de Adell en base a Dieste, para la nueva cubierta de las Escuelas de Gaudí, apenas sería perceptible formalmente en dicha obra, permitiendo construir dos tipos de cubierta diferenciados por sus apoyos:

1. Cubierta de doble curvatura apoyada solamente en la viga central y volada sobre las paredes de las fachadas longitudinales, de tal manera que podría dejarse una junta abierta (y acristalada con pavés)
PROPUESTA NUEVA CUBIERTA DE GAUDÍ - DIESTE - ADELL

\section{nueva cubierta sin viga ni pilares ni cumbrera central con tres voltas tabicadas y aislamiento intermedio}
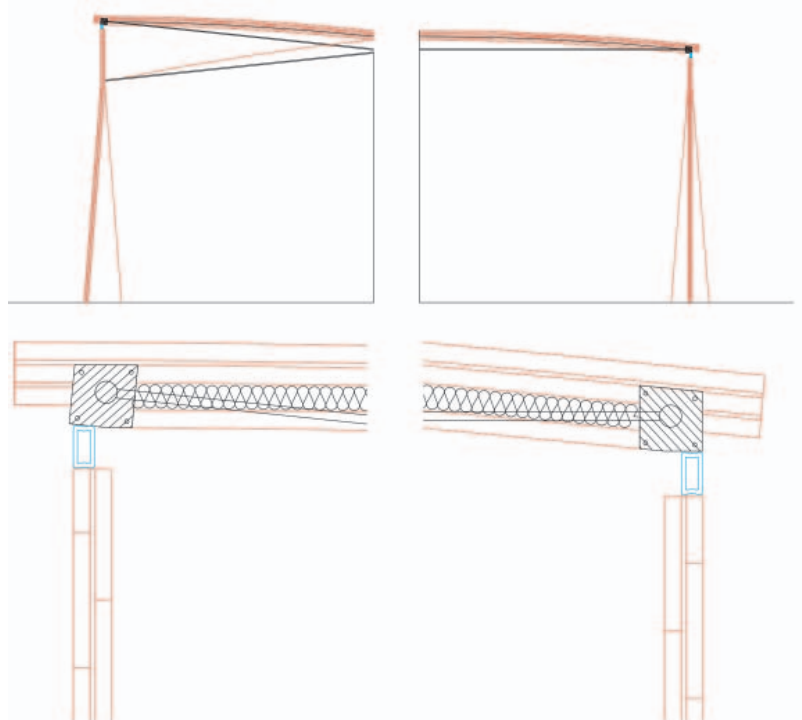

DETALLES DE LAS SECCIONES TRANSVERSALES

DE LA CUBIERTA ATIRANTADA Y DE DOBLE CURVATURA PROPUESTA POR J.M. ADELL CON EL RESPALDO DE DIESTE

Fig.IV.7. Vistas de la cubierta Gaudi-Dieste-Adell en su segunda variante de apoyo en las fachadas longitudinales, eludiendo los pilares y la viga central.

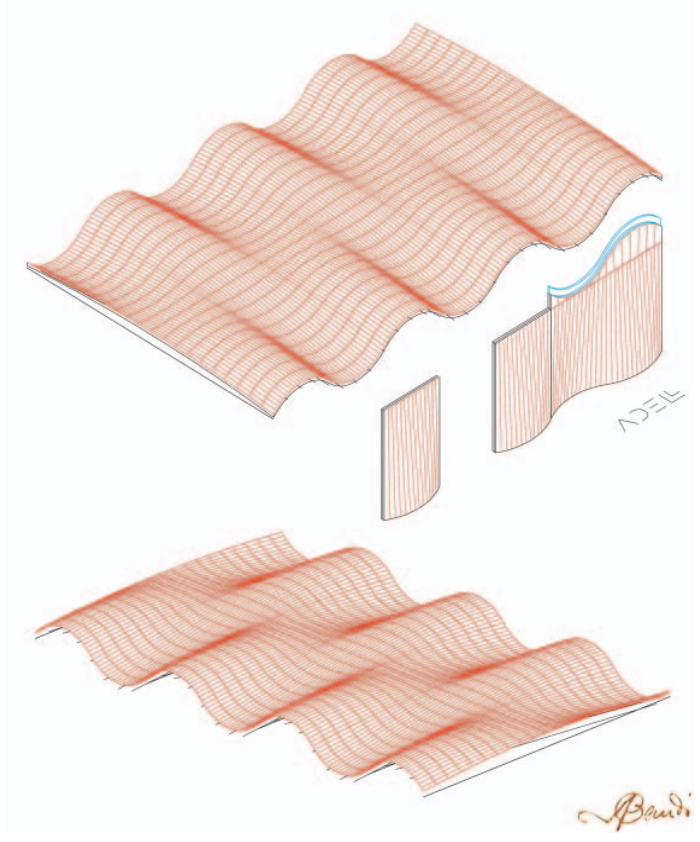

Fig.IV.8. Detalles de la cubierta anterior donde se aprecia que se puede resolver incorporando aislamiento central para la adecuada habitabilidad higrotérmica del nuevo espacio cubierto de las Escuelas de la Sagrada Familia de Gaudí. 
entre la cubierta y la fachada, que iluminara el interior de las Escuelas, reflejando la novedad de la cubierta respecto de la original quemada en la Guerra Civil (Fig.IV.5).

Comparando entonces la cubierta original de Gaudí, que tenía una cumbrera central para evitar la acumulación de agua en su zona central del apoyo sobre la viga intermedia (ya que la deformación en el apoyo discontinuo de los tablones de madera crea un remanso de agua), la nueva cubierta de Gaudí-Dieste-Adell, gracias a su doble curvatura, nunca permitiría el remanso del agua y, por lo tanto, podía prescindir claramente de la cumbrera central, ya que se trata formal y técnicamente de una sola bóveda con varias ondulaciones.

La sección transversal de esta nueva cubierta, sin cumbrera central, podía alojar la viga de apoyo entre el vacío generado por la nueva curvatura, y los tirantes dispuestos en el lugar de los tablones, dejando el espacio más liberado de estructura, pudiendo disponerse sólo 2 soportes para el conjunto (Fig.IV.6).

2. Cubierta de doble curvatura sin apoyo central (y, por tanto, sin vigas ni pilares que subdividan el nuevo espacio rehabilitado), apoyándose solamente en ambas fachadas longitudinales, lo que no impedía hacerse también sobre una zona acristalada, para diferenciarla de la incendiada en su día (Fig.IV.7).

La doble curvatura de esta nueva cubierta, también evitaría la necesidad de la cumbrera, eludiendo que el agua se encharque en su zona central.

La rehabilitación de la cubierta para un espacio habitado con la eficacia higrotérmica que se exige en la actualidad, aconseja añadir cierto aislamiento en la misma, por lo es posible incorporar placas aislantes entre las hojas de fábrica atirantadas de la nueva cubierta de Gaudí-Dieste-Adell (Fig.IV.8).

\section{CONCLUSIONES}

Como se ha demostrado pormenorizadamente, las vicisitudes de las Escuelas de la Sagrada Familia por los incendios provocados, y por la desafortunada decisión de la técnica de traslado partiendo de su despedazado, han llevado a que apenas queden partes originales de Gaudí.

Además, y apoyándose en la desafortunada rehabilitación de Quintana en 1940, se ha tergiversado la autenticidad de la obra de Gaudí en lo que a la cubierta se refiere, sin llegar a poderse entender que se trataba en sí misma de una obra experimental para el posterior desarrollo de las cubiertas del Templo.

Por la oposición de la J.C.T., no ha sido posible reubicar las Escuelas sobre un espacio donde pudieran ser apreciadas con su total originalidad e integridad y nuevamente han quedado "aparcadas" a los pies del Templo, aunque en otra fachada.

Tampoco ha sido posible desarrollar las investigaciones propuestas que esta obra ha suscitado, tanto a este autor como al Arquitecto uruguayo Dieste, en la búsqueda de una solución más adecuada con la evolución de las técnicas en el tiempo.

\section{BIBLIOGRAFÍA}

- Essay on the Theory and History of Cohesive Construction, applied especially to the timbrel vault. Guastavino, R. Ed. Ticknor and Company. Boston 1893 (Bóveda tipo "barril”, fig. 45; pág. 103).

- Tabicados Huecos: "Estudio experimental de los elementos para bóvedas del templo gaudiniano”. Bergós Massó, J. Ed. Colegio Oficial Arquitectos de Cataluña y Baleares, 1967.

- Gaudí el hombre y la obra. Bergós Massó, J. Ed. Universidad Politécnica de Barcelona 1974. Cátedra Gaudí. ISBN 84-600-62481 (págs. 102-103).

- Rationalist met perfecte materia albeheersing. Molema, J. Capítulo: "Schooltje bij de Sagrada Familia". Wijnand Looise. Ed. Delft University Press. The Netherlands 1979 (págs. 147-152).

- Las bóvedas de la Atlántida. Adell. J. M. Revista Informes de la Construcción. Vol. 44. $\mathrm{n}^{\circ}$ 421. Instituto Eduardo Torroja. Consejo Superior de Investigaciones Científicas. Madrid, septiembre/octubre, 1992 (págs. 113-123).

- Las Escuelas de Gaudí o la síntesis entre la técnica y el arte. Adell, J. M. IV Jornadas Internacionales Estudios Gaudinistas. Barcelona, 13-15 noviembre 1997

- Patente de Invención: "Sistema para movilización o desplazamiento de edificios". Adell, J. M. Madrid, 10 de febrero de 1998. Evaluada y concedido Certificado-Título. Desarrollada para mover las Escuelas de la Sagrada Familia de Gaudí.

- Traslado, ubicación y uso. Adell, J.M. V Jornadas Internacionales de Estudios Gaudinistas (págs. 83-93). Reus, 12 al 15 de noviembre de 1998

- The moving of Guadi's Sagrada Familia Parish School in Barcelona. Adell, J.M. Paper $12^{\text {th }}$ International Brick/Block Masonry Conference. 25-28 Junio. Madrid 2000 (págs. 169-180).

- Las Escuelas de Gaudi en la Sagrada Familia: I. Pasado II. Presente y III Futuro. Revista Informes de la Construcción Inst. Eduardo Torroja. Febrero 2002.

- Unas Escuelas polémicas. Cabré, T. Artículo publicado en el diario La Vanguardia, con referencias de J. M. Adell sobre el traslado del edificio de forma integral. Barcelona 9 de marzo de 2002.

- Escuelas de Gaudí: Proceso de traslado. Ateneo de Barcelona: SOS Monuments. 6 de Febrero 2002. Constatación de "El Gaudí Despedazado: las ESF" (07/03/02).

- Gaudí en Madrid: ciclo de mesas redondas. Madrid abril-mayo 2002.. Capitulo "Gaudi y el Modernismo". Adell, J. M. Ed. Fundación Independiente. 2002. ISBN 84-921922-8-3 (Texto de la presentación en la mesa redonda en el Círculo de Bellas Artes, págs.158162).

. Aportación sobre el "Traslado de las Escuelas de Gaudí" en la Mesa Redonda del Ateneo (pág. 83).

·Aportación sobre "La conservación de las Escuelas de Gaudí" en el Colegio de Arquitectos de Madrid (pág.116).

-Presentación del libro de las Mesas Redondas en la Editorial Blanquerna 2003.

- Las Escuelas de Gaudí: Traslado y Reconstrucción de la Cubierta. Adell, J.M. Seminarios Torroja. Madrid. 11/04/2002. 